E International

\title{
Contemporary Airport Demand Forecasting
}

Choice Models and Air Transport Forecasting

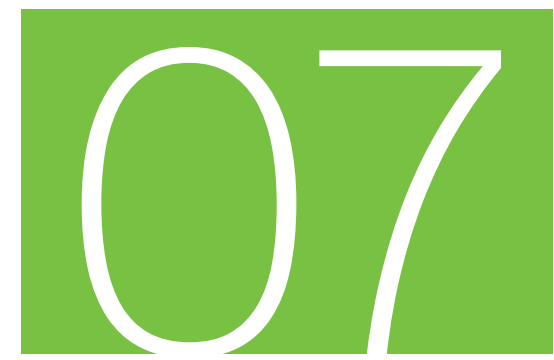

Discussion Paper 2014• 07

Benedikt Mandel

MKmetric GmbH,

Karlsruhe, Germany 


\section{International Transport Forum}

\section{Contemporary Airport Demand Forecasting}

Choice models and air transport forecasting

Discussion Paper No. 2014-07

Benedikt MANDEL

MKmetric GmbH, Karlsruhe, Germany

April 2014 
The International Transport Forum at the OECD is an intergovernmental organisation with 54 member countries. It acts as a strategic think-tank, with the objective of helping shape the transport policy agenda on a global level and ensuring that it contributes to economic growth, environmental protection, social inclusion and the preservation of human life and well-being. The International Transport Forum organises an annual summit of Ministers along with leading representatives from industry, civil society and academia.

The International Transport Forum was created under a Declaration issued by the Council of Ministers of the ECMT (European Conference of Ministers of Transport) at its Ministerial Session in May 2006 under the legal authority of the Protocol of the ECMT, signed in Brussels on 17 October 1953, and legal instruments of the OECD.

The Members of the Forum are: Albania, Armenia, Australia, Austria, Azerbaijan, Belarus, Belgium, Bosnia and Herzegovina, Bulgaria, Canada, Chile, People's Republic of China, Croatia, Czech Republic, Denmark, Estonia, Finland, France, Former Yugoslav Republic of Macedonia, Georgia, Germany, Greece, Hungary, Iceland, India, Ireland, Italy, Japan, Korea, Latvia, Liechtenstein, Lithuania, Luxembourg, Malta, Mexico, Republic of Moldova, Montenegro, the Netherlands, New Zealand, Norway, Poland, Portugal, Romania, Russian Federation, Serbia, Slovak Republic, Slovenia, Spain, Sweden, Switzerland, Turkey, Ukraine, United Kingdom and United States.

The International Transport Forum's Research Centre gathers statistics and conducts co-operative research programmes addressing all modes of transport. I ts findings are widely disseminated and support policymaking in Member countries as well as contributing to the annual summit.

\section{Discussion Papers}

The International Transport Forum's Discussion Paper Series makes economic research, commissioned or carried out at its Research Centre, available to researchers and practitioners. The aim is to contribute to the understanding of the transport sector and to provide inputs to transport policy design.

ITF Discussion Papers should not be reported as representing the official views of the ITF or of its member countries. The opinions expressed and arguments employed are those of the authors.

Discussion Papers describe preliminary results or research in progress by the author(s) and are published to stimulate discussion on a broad range of issues on which the ITF works. Comments on Discussion Papers are welcomed, and may be sent to: International Transport Forum/OECD, 2 rue André-Pascal, 75775 Paris Cedex 16, France.

For further information on the Discussion Papers and other JTRC activities, please email: itf.contact@oecd.org

The Discussion Papers can be downloaded from:

www. internationaltransportforum. org/jtrc/DiscussionPapers/jtrcpapers.html

The International Transport Forum's website is at: www. internationaltransportforum.org

This document and any map included herein are without prejudice to the status of or sovereignty over any territory, to the delimitation of international frontiers and boundaries and to the name of any territory, city or area. 


\section{TABLE OF CONTENTS}

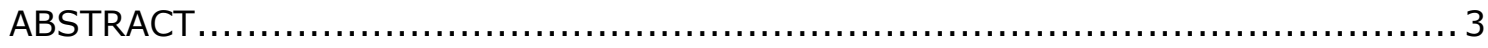

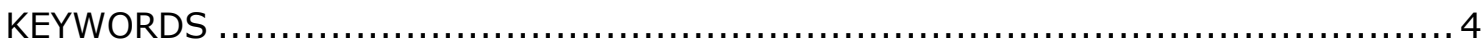

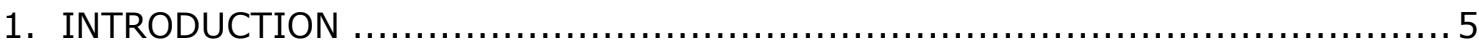

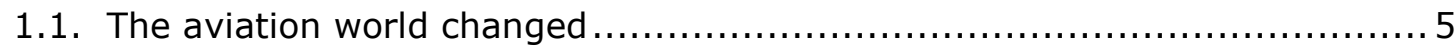

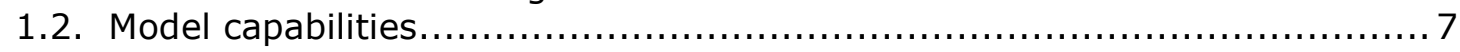

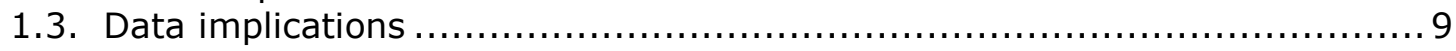

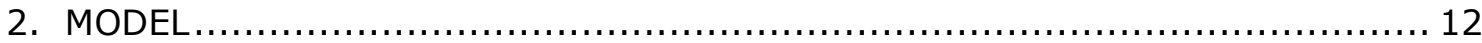

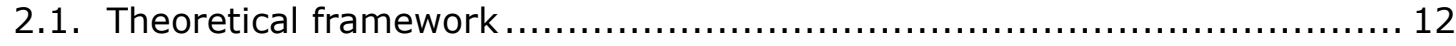

2.2. Reflection of the status quo as reference point $\&$ scenario simulation....... 20

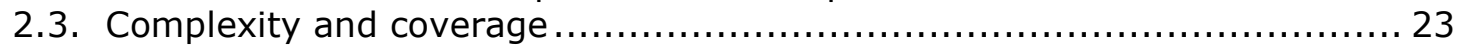

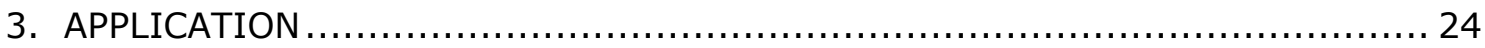

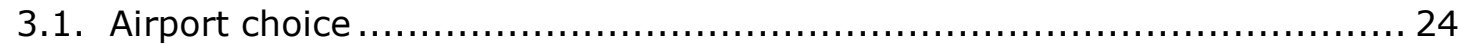

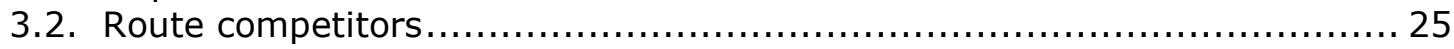

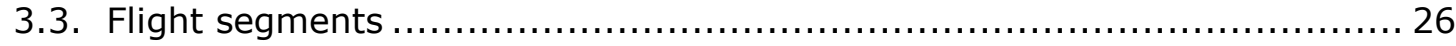

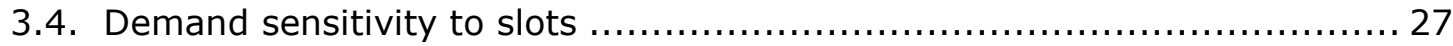

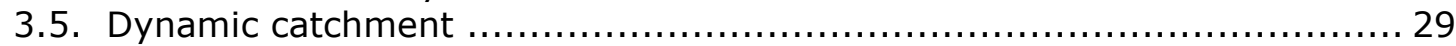

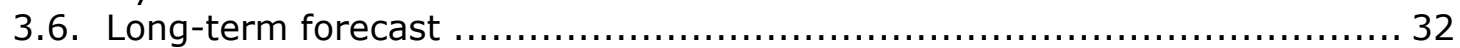

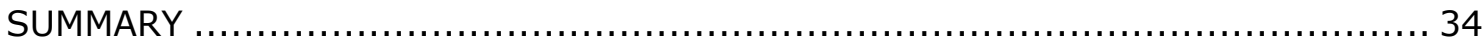

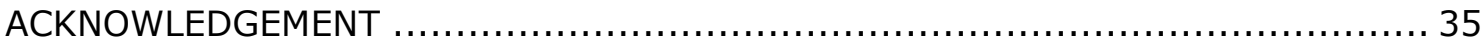




\begin{abstract}
This paper describes the econometric system approach developed by MKmetric to perform short and long-term air transport demand forecasts while considering various determinants such as socio-economy, policy, infrastructure and land use. The necessities for modelling air transport evoking from a transport system point of view and the changes of the aviation world occurred during the last decade are investigated. Based on these findings the mathematical framework is outlined considering shortfalls of traditional models used in aviation forecasting and restrictions caused by classical functional forms. The increasing gap of information for modelling is described and alternative data sources used for the development of the system approach are listed. As all models are imperfect describing just a part of real life, it sheds a light on the necessity to validate models and the prerequisite of complexity needed to cope with multi-sector scenario simulations for strategic, tactical and operational developments as well as political decisions. Finally some analysis examples demonstrate the power of the approach used focusing on the choice modelling reflecting consumers' behaviour.
\end{abstract}

\title{
KEYWORDS
}

System approach, passenger demand, short-term, long-term, forecast, choice models, non-linearity, consumer behaviour, elasticity, spatial competition, BSP, MIDT, data gaps, network, access-egress choice, airport choice, route choice, dynamic catchment, multimodal, inter-modal, intra-modal. 


\section{INTRODUCTION}

There are various situations where airport demand forecasting is requested to provide facts for decision makers either on route development, airline marketing, infrastructure investment, competition analyses, risk assessment and policy or entrepreneurial tactical and strategic simulations of scenarios. These questions can be addressed to a short, medium or long term horizon for passenger market potentials. Thus there are different user groups with different targets but all focus on change of demand, effects on the supply side and the consumers respectively market behaviour under changing conditions, which is the core of consumer choice modelling in context of demand forecasting.

While politicians might want to know the effects of taxation, bilateral agreements or the necessity of infrastructural investments for upgrading an existing or building a new airport, the regional authorities as airport owners might concentrate on the overall question of an airports' passenger potential or on PSO (public service obligation) routes to increase the regional accessibility, the airports may address questions concerning new routes to develop the destination portfolio and airlines are concerned with the enrichment and rearrangement of their network. There are plenty of questions to which the approach described in this document can supply added value for the stakeholders, but all of them in common require to forecast demand under changing supply conditions, thus a passenger market potential analysis based upon a consumer behaviour sensitive model reflecting the competitive transport situation is necessary.

The model itself needs to be flexible so that long term forecasts can be done (ex ante) as well as short term simulations (ex post) are possible to enable consistency. The long term forecast covers all effects starting from the generation of traffic based on socioeconomic attractors while the short term simulation concentrates on the existing traffic checking the consumers' reaction on changes in the supply side. The latter is the most interesting for airlines and airports working at development perspectives of the air services taking into account the offers available at competing airports and their catchment areas encountering interdependencies between new and existing services in the air transport system as a whole.

\subsection{The aviation world changed}

Since decades procedures have been designed to predict the air transport market developments and models have been capable to forecast securely air passenger demand potentials based on historic data (statistics) and full market samples (BSP, MIDT). These standard approaches are uni-modal focusing solely on air transport and a specific airport. For the determination of connectivity measures network variables are used, which derived from commercial available schedule sources such as OAG.

But since the 90 's the market situation changed strongly as liberalisation, deregulation and globalisation have been enormous drivers with strong influence on the aviation market. Thus the aviation industry has been faced with a differentiation inside the airline 
world so that beside network, regional and charter carriers the new low cost / low fare airlines and hybrid carriers combining all kind of services evoked. The intensified liberal air service agreement policy tore down barriers and opened new markets while competition increased. The latter leading to necessary consolidation in the airline world by mergers and acquisitions all around the world (in Europe IAG, AF/KLM, Lufthansa Group, and Air Berlin), which is still ongoing. One consequence has been the rise of global airline alliances to defend markets, leverage synergies and to influence consumers' behaviour by customer loyalty programmes.

Furthermore military airports have been converted to civil ones or have been upgraded respectively build. And airlines have been newly founded or dramatically boosted their business, especially when looking to the Gulf region. These Gulf airlines placed huge aircraft orders with focus on the new developed aircrafts allowing to draw from economies of scales, operating with lower costs and to offer multiple attractive destinations due to the aircrafts' range. In consequence new hub facilities have been established enriching the portfolio of consumers' choice set while enhancing the competition among airlines. In the meantime all airlines react and upgrade their fleet by new aircrafts such as A380, B787, A350, A320 neo, B797, CS-Series, etc. which allow a higher efficiency, productivity and more flexible operation. Also new products on board have been developed and a higher differentiation in the fare structure with tariff decomposition driven by aggressive yield management came up. Especially the hub \& spoke services are marked very sensitively to supply and demand changes, so that special offers make detours attractive.

With the globalised economy and the free settlement across the European Union member states as well as the new service products new markets raised as consumers undertake more short trips. Also migration loops back allowing to serve new destinations, VFR and multiple leisure trips by air became more affordable. Last but not least the consumer has been educated to be more sensitive to price and other product attributes, which was supported by the IT-systems with web based platforms making offers easily transparent. In consequence the airlines and airports are faced with new type of consumers with different behaviour, requesting modern communication (e.g. internet, Facebook, Twitter, YouTube) and distribution channels (internet, kiosk, mobiles, social media). Together with the cost pressure due to competition airlines boost direct sales channels avoiding global distribution system (GDS) costs whenever possible although such internet based GDS increased their sales power (Expedia, Opodo, etc.). But the competition is not just between airlines or air alliances respectively on flight segments and routes, it takes place as well between airports irrespectively whether these are hub or spoke airports. On top it has to be mentioned that there is a kind of symbiotic relationship between the air and rail mode as the high speed rail services compete with air services (e.g. Lyon-Paris, Frankfurt/Stuttgart/Strasbourg-Paris, Barcelona-Madrid, all around Germany) and at the same time airlines with no air feeder system use these rail services to link their products to a wider spread market by offering rail \& fly products. The competitive situation is as well inspired by new regulations such as strengthened passenger rights and emission trading scheme or more local environmental fees respectively national taxes on air services.

Finally the formerly stable markets became unstable as schedules change faster, especially the low cost carriers often follow the try \& error principle, and economic drivers like GDP, kerosene price, or bank crises are peaking with high variance. Unpredictable are global disease effects (e.g. SARS, bird flu) and environmental catastrophes (e.g. volcano eruption, hurricanes, earth quakes, flooding) as well as terror acts, all leading to increased safety and security efforts. 
The section could be easily extended but it should just show that too much has changed so that the classical forecasting approaches based on trends of the past or service of quality prolongations (SQI) neither reflect the radical market development nor cope with the increasing data leakage as direct sales remain proprietary information. To respect the challenges outlined before and to incorporate functionalities to deal with the new market developments, models must mirror the point of view of consumers more detailed. Usually people neither live nor work or make holidays at airports. For the majority the origin and destination of a trip are locations in the vicinity of airports respectively the region. Therefore the models' point of view has to turn from the airport to the region as starting point of the trip decision so that the traditional static view becomes a consumer oriented dynamic one. Thus airport catchments are no longer defined by fixed isochrones to determine the airports' passenger potential; they are flexible reflecting the competitive situation route by route.

\subsection{Model capabilities}

The challenges outlined a demand forecast reflecting the passenger market potential is facing need to be treated by an adequate forecasting method. With focus on air transport forecasting effects of future actions any market changes have to be measured or considered within a consistent modelling approach. Irrespective which mathematical form is used at least the following instances need to be reflected:

$>$ competition of destinations, e.g. complementary or substitution

- Regions are competing with each other for inbound tourism and investments to increase employment and finally welfare of the population. Thus the accessibility by air of a region is an important asset for its development perspectives. Parallel decreasing travel costs allow consumers to use the money saved for additional trips or to combine several destinations.

$>$ competition of modes (multimodality), e.g. air, rail and road

- The surface networks are extended all around the world and especially high speed rail services offer alternative travel options which can easily compete with air services due to attractive travel times and prices.

$>$ co-operation of modes (inter-modality), e.g. air-rail, air-road

- The extensions of surface networks allow an intensive co-operation of modes as well. Beside the classical highway access especially airport railway stations embedded in a high speed rail network qualify best to increase the catchment area of an airport to substitute feeder flights and to offer rail \& fly services.

$>$ competition within the aviation mode (intra-modality), e.g. airports, airlines

- A high density of airports with overlapping destination portfolios from different type of carriers favours competition. Starting the trip from a region there is the opportunity to choose among different originating airports and one could arrive at different airports at the destination area which is not only the case at multi-airport cities: One also has to consider how intensively those airports are embedded in the surface transport networks. Looking at each originating airport, the different choices for air services has to be considered too. Beside nonstop flights there are often offered plenty of different transfer routes, in some cases even from the 
same airline / alliance. In case of transfer connections the hub airports / airlines are competing as well which enhances the necessity to consider various route alternatives. All alternative air services together reflect the consumers' choice set and the competitive situation where catchments overlap and airports / airlines highlight the strengths of their product (e.g. time, price, frequency, operation days, slots, capacity, ASA) to attract passengers.

$>$ interdependency of the different decision levels of the consumers, e.g. slot choice, airport choice, access/egress choice, mode choice and travel demand

- As a trip does not start at the airport door one has to consider the whole travel chain starting from access/egress of airports, the time slice the trip takes place, and the route taken. Moreover the attractiveness of an air trip versus other modes or even whether a trip can be undertaken (budget of time, financial welfare) determine the consumers decision or choice respectively.

$>$ sensitivity of the consumers to supply changes, e.g. elasticity of level of service variables, thresholds, captivities

- Different types of consumers show different sensitivities to product characteristics. While some travellers are very time sensitive and request a high frequent service during the day and at any day of the week, other travellers are more cost sensitive and first look for low prices and find just one flight per week sufficient to be carried just in time to their holiday location. The consumers behave non-linear and have different thresholds where they reconsider their decision; they might be captive to product types and inelastic to pricing while travel time is dominating their choice most. The models need to reflect the consumers' utility ideas by embedding the travel alternatives' characteristics (e.g. time, cost, frequency, operation days, alliance or online connection) in the functional form.

synergetic power of networks, e.g. air alliances, hub \& spoke, high-speed rail

- There are different air service products on the market and beside point to point services large networks are operated evoking massive hub \& spoke systems around the world. Instead of just analysing and forecasting the demand potential of one airport today thinking in networks to cover local and global effects in parallel is a necessity. Consumers with a low value of time accept huge detours and there are airports serving more transfer passengers than local traffic. Routes are developed based on the scaling effects a hub system allows benefiting as well from alliances among airlines. The place an airport occupies in the market reflects the relative position as competitor, whereby the networks (of air services as well as of access/egress surface modes) define the impedances and the attractiveness. Without considering the synergies of networks at the airport in focus and as well the ones of its competitors it is neither possible to locate the market position today nor in future.

$>$ economic valence and ecological balance

$>$ For a stable forecast it is essential that the air services are of economic valence as beside some PSO routes reflecting cohesion policy no subsidised network can be 
maintained in long-term as sustainable transport system. Moreover the system must be in line with the international competition rules and able to bear its external costs such as the emission scheme imposed by the EU.

The following figure depicts the emphasis outlined above in a striking way.

Figure 1. Consumers' complex alternative travel opportunities

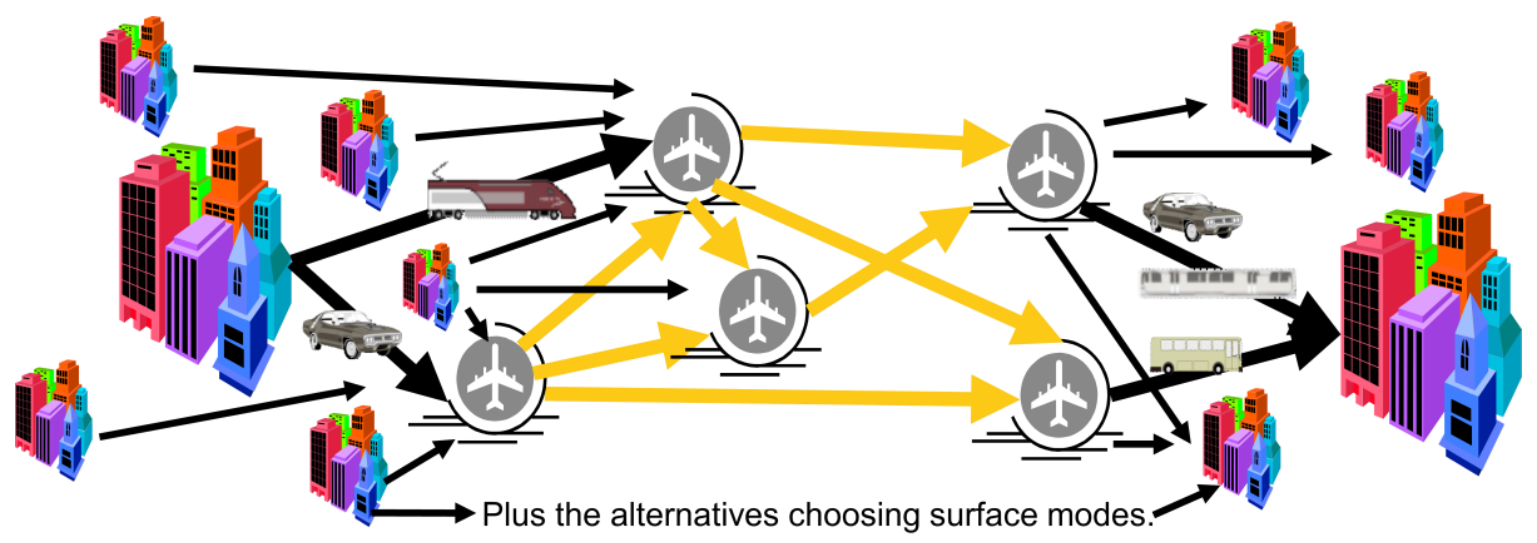

Source: MKmetric, 2014

Furthermore air transport is determined by external factors. They concern the socioeconomy (e.g. population, GDP, ex-/import), technology (e.g. infrastructure, motorization, vehicle / propulsion types), urbanisation (land use, population / economy density), and policy (national / international constraints, regulations, agreements).

Considering these market circumstances the model will be able to quantify, analyse and evaluate effects on travel demand and consumer reactions to planned actions for shortand long-term investigations. To satisfy all criteria mentioned above a consistent system approach with various econometric models dealing with the different requirements, implications and dynamic networks have to be used allowing to explain all interdependencies in parallel so that no transport activity remains unexplained or will be lost. Neither an airport focused trend forecast nor a QSI model allows capturing these different effects and interdependencies.

\subsection{Data implications}

Following the argumentation above one need to shed a light on the data implications necessary to establish, validate and run such a model approach.

The historic workhorse of MIDT / BSP databases, which have been a splendid source of information in the past, do neither cover all necessary data aspects nor ensure the requested quality due to dramatic reductions in sample size and the exclusion of markets such as LCC and Charter. Even IATA stated this fact (Symposium Istanbul 2010) and mentioned that in consequence products like PaxIS are no longer of value added for airports and airlines (Symposium Singapore 2012). It was stated by Bryan Wilson 1 that PaxIS has lost $35 \%$ of total data (70\% in Europe), and that it is no longer useful for many clients. (Please note that the BSP/MIDT data sources never covered Charter and LCC data, thus the total market coverage is even much smaller.)

1. http://www.worldtek.com/wp-content/uploads/2011/10/Direct-Data-Services-Wilson.pdf 
In parallel to the shrinking data sample the Global Distribution Systems (GDS) like Abacus, Amadeus, Galileo, Infinity, Sabre, Travelport, Travelsky, Worldspan etc. are fighting to defend their Marketing Information Data Tape (MIDT) dominance and there are heavy legal challenges ongoing about the use of the BSP data. GDS provider want to protect and invent own products with customized solutions. In 2011 IATA reacted to the insufficient data situation by offering an alternative product, the Direct Data Service 2 (DDS). The product idea is not revolutionary and the challenge is with the data provider. IATA invites travel agencies, airlines, and airports to share data on different granularity levels by signing a Contribution and License Data Agreement (CLDA). Just the ones who signed in have access to the collected data according to the agreement signed. But given the increased competitive situation and the strong engagement of carriers into direct sales techniques, why should airlines and airports provide these data to IATA-DDS so that competitors gain knowledge about markets to explore? Airlines already hardly share all market respective sales data within an alliance.

According to SITA, who regularly undertakes IT trend surveys 3 covering the 200 largest airlines worldwide the tendency to direct sales will even be intensified and diversified. The survey launched in 2013 shows that until 2016:

- $\quad 97 \%$ of the airlines will strongly invest into personalized and mobile customer services

- $\quad 90 \%$ of the airlines will offer tickets via mobile phones

- Share of boarding passes by apps on mobile phones will increase from $53 \%$ to $80 \%$

- The share of direct sales by airlines will increase from $54 \%$ to $67 \%$

- $65 \%$ of airlines offer mobile schedules already today (2013)

- $61 \%$ of airlines offer mobile check-in already today (2013)

- $60 \%$ of airlines will offer service on lost baggage

- $63 \%$ of airlines will offer services to change reservations

- $\quad 57 \%$ of airlines will offer services to allow for feed back

- The value of GDS ticket sales will decrease from $46 \%$ to $33 \%$ of the turnover of classic travel agents

- $\quad 14 \%$ of all ticket sales will be executed by mobile phones, social media and full automatic sale stations

These survey results of SITA are reconfirmed by airline managers like Lionel Guérin ${ }^{4}$, Chairman and CEO of HOP (Brit Air, Regional and Airlinair) monitor as well. He stated in

2. http://www.directdataservice.com/

3. http://www.sita.aero/surveys-reports/industry-surveys-reports/airline-it-trends-survey-2013

4. http://corporate.airfrance.com/en/press/news/article/item/3-questions-for-lionel-guerinchairman-and-ceo-of-hop/ 
an interview on 29.01.2013: "The other main new trend concerns the explosion of online sales: over $60 \%$ of Europeans systematically buy their airline tickets on the internet."

The direct sales channel does not just help airlines to become more cost effective, they also can optimise the data usage for personalized services to customers maximising the sale of add on services. The SITA study outlines that the sales of additional services will become much more important as airlines generate nearly nine times higher sales when purchasing the tickets to customers directly. Referring to the published business reports of the LCCs this argument holds. In consequence, the airlines are forced to intensify their direct sales efforts due to the multiple beneficial effects and the competitive advantage they can materialize. Due to globalisation and the strong competition airlines in all areas of the world diversify their business model as a logical step forward. As side effect the airlines reduce their dependence on distributors and save related costs when increasing mobile sales and other direct sale services.

Thus the traditional commercial data sources (BSP / MIDT) and the new products offered by IATA and the GDS provider are faced with declining samples and therefore depend on data gap-handling procedures to forecast the total market based on fragments of information as if any, often just the indirect sales data are available in the databases reflecting a small share of all sales and still LCC and Charter are missing. Beside the aforementioned data problem the classical forecasting tools have to cope in parallel with the market and consumer behaviour changes rising the risk of the forecasts' quality. This concerns not only the long-term investigations, also the classical Service of Quality Index (SQI) approaches struggle with a rapidly declining base of information resulting into a lack of quality.

In consequence for the forecasting task the fragmented commercial available MIDT / BSP data are not sufficient, neither in coverage and quality nor in dealing with the outlined challenges. Other data sources are needed to compensate the shortfalls and to cope with the model requirements. In the following the main data types are listed enabling a model development based on public and mostly free data sources ${ }^{5}$ :

> Volume observations to cover the whole transport market, e.g.

- detailed Eurostat and national statistics (on flight, on stage)

- publications of airports and airlines, IATA samples*

- publications of airport and airline associations

- link counts for road

- transport figures for rail

$>$ Consumer elasticity to identify the consumers' sensitivity, e.g.

- air transport passenger surveys at airports across Europe6*

- mobility and travel surveys across Europe

- panel data of households

5.* Indication for commercial data source

6. Having access to the $10 \%$ ticket sample in the US as non-US citizen and combining this with a $10 \%$ ticket sample for Europe, which is technically possible with minor effort and costs for airlines, would open a new dimension for researchers and modelling. 
> Mode networks to mirror the consumers' choice set, e.g.

- air schedules (OAG, Cedion, Innovata, ...) 7*

- air traffic management data (EUROCONTROL, national representation)

- information from the air transport industry (destination portfolios, load factors, ...)

- surface networks (road, bus)

- railway, ferry schedules*

$>$ Regional indicators to diversify regional attractiveness, e.g.

- socio-economy (UN, IWF, OECD, EZB, Eurostat, ...)*partly

- satellite data (Corine aggregates, ...)

- tourist information

- land use data

- meteorological and geological data

These data allow building up, validating and running a forecasting model. The methodology to be applied is explained in the following section, whereby the basics of the econometric part are outlined while for the details it is referred to the publications available on our web site www.mkm.de.

\section{MODEL}

Within this section the principle method and models are described which are used by MKmetric to deal with the requests of forecasting transport demand under consideration of the global transport market in parallel. The basic mathematical form of the models is displayed and publications are listed to study in depth the mathematical details of the econometric models. In addition the description provides the essential characteristics and features a model must reflect when dealing successfully with the challenges and requirements for forecasting as outlined above.

\subsection{Theoretical framework}

The forecasting procedure and the resulting analyses are based on a consequent systematic view of transportation. It is therefore necessary to embed air transport forecasting and simulation in a framework of relevant relationships that take into account the whole transport market as well as demographic, economic, political, spatial and technical components. A modelling process based on these interrelationships explains the

7. EUROCONTROL refuses sharing schedule related data with the argument the information belong to the airlines, which is disconcerting as airlines publish schedules but unfortunately not at one place consistently. 
transport market by multimodal and multi-sector determinants. This approach ensures the consistency of the whole model system in every step of the simulation process as the models always process balanced figures of all endogenous measures. Hence, no transport activity appears or disappears unexplained within the system. Changes in the system's state are substitutive or complementary and synergetic effects lead to new situations concerning diversion, accessibility or attractiveness. These effects can be analysed with respect to modes (e.g. road, rail, sea, and air) and/or trip purposes (e.g. business, vacation, private).

In the light of the complexity outlined in the previous chapters it is obvious that there must be a sequence of models dealing with all the interrelationships and dependencies to catch the consumers' behaviour. The system approach developed is based on the classical 4 step procedure, namely generation, distribution, modal split and assignment. There are some differences in combining steps, modelling techniques, functional form and additional modelling steps to cope with specific effects within air transport. The following figure shows the principle structure.

Figure 2. Sequence of models for air transport forecasting

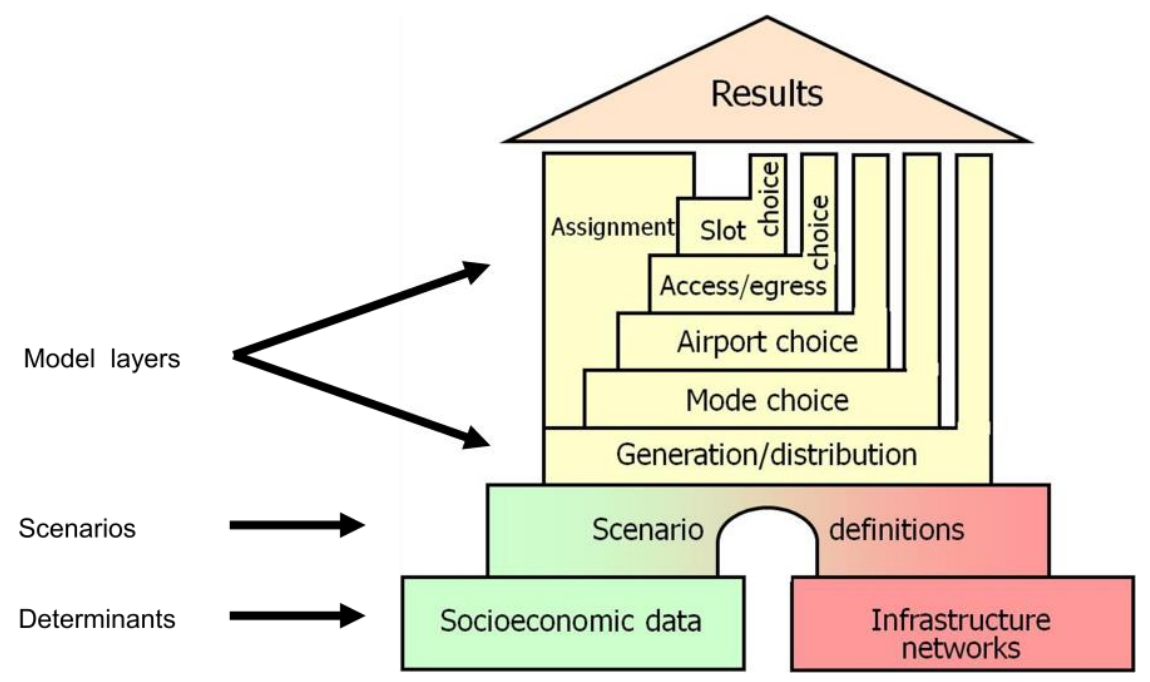

Source: MKmetric, 2014

The basis of all models contains the determinants of transport. It is the data base where all information is stored to run the models, e.g. socio-economy, regional attractors, networks. The second block defines the scenarios to be tested. Short-term scenarios are often used to execute ex post ${ }^{8}$ forecasts investigating a specific question, e.g. changes in network, competition, air service agreements or taxation. Long-term scenarios are mainly used for ex ante forecasts and contain a bunch of assumptions such as socio-economic development, infrastructure investments, capacity constraints, airline strategies or policy measures. In principle the scenario definitions can encompass all input data for the models and any measures with quantitative influence on the model variables. The richness of a scenario definition depends on the level of granulation the models determine.

The first modelling block concerns the generation-distribution model. It computes the total traffic volumes, where they emerge and whereto they are directed. There are models splitting the demand and the distribution of traffic, whereby first the mobility

8. What effects appear in case a certain activity would have taken place in the reference year. 
pattern and then the demand distribution is computed. Here we follow the combined generation-distribution approach to incorporate in parallel the substitution and complementarities of destinations and to deal with the requirement of spatial competition. In the following the principle mathematical form is displayed, for more details see the papers listed below ${ }^{9}$.

The flow $T$ from region $i$ to region $j$ is computed by a non-linear function $g^{d}$ with socioeconomic factors $A(a=1, \ldots, A)$ and the modes utility, e.g. network impedances, $U$ $(\mathrm{m}=1, \ldots, \mathrm{M})$ as follows:

$T_{i j}=g^{d}\left(\left\{A_{i j_{a}}\right\},\left\{U_{i j_{m}}\right\}\right)$ with $\quad A_{i j_{a}} \equiv\left[S_{i_{a}}^{1 / 2} S_{j_{a}}^{1 / 2}\right]$

whereby S reflects variables like GDP, population, purchase power, income and

$U_{i j_{m}}=e^{v_{i j_{m}}}$

whereby $v$ is an additive non-linear function of network impedances like time and distance under consideration of all modes and consumer related data like age and gender.

As regression problem one can formulate the above into a simple multiplicative form, such as:

$T_{i j}=\beta_{0} A_{i j_{1}}^{\beta_{1}} \ldots . A_{i j_{A}}^{\beta_{A}} U_{i j}^{\beta_{U}} u_{i j}$

To detect and gain the non-linear effects Box-Cox transformations (BCT) of the strictly positive variables are applied. To guarantee for a constant variance a variable correcting heteroscedasticity is imposed. The error term is analysed under consideration of nonlinearity $(B C T)$ to extract functional information so that a pure stochastic term is left.

The functional form is enriched by a vector describing the dependencies of neighbouring regions as destination of a trip so that one can cope with the problem of irrelevance of spatial competition which is inherent due to Luce's IIA axiom.

Given the following situation we assume region 2 and region 7 to be close substitutes.

9. Entwicklung eines gekoppelten Verkehrserzeugungs- und verteilungsmodells für den Personenfernverkehr - Development of a linked trip generation and distribution model for long distance passenger traffic, on behalf of the German Ministry of Transport FENr.: 60307/92; Université de Montréal Centre du Recherche sur les Transports (C.R.T.), MKmetric $\mathrm{GmbH}$, University of Karlsruhe (TH) Institute of Economic Policy and Research (IWW); Gaudry M., Mandel B., Rothengatter W.

Introducing Spatial Competition through an Autoregressive Contiguous Distributed (AR-C-D) Process in Intercity Generation-Distribution Models within a Quasi-Direct Format (QDF), Université de Montréal C.R.T., MKmetric GmbH Karlsruhe, Universität Karlsruhe (TH) Institute of Economic Policy and Research (IWW); Gaudry M., Mandel B., Rothengatter W.; CRT-971 


\section{Figure 3. Spatial competition}

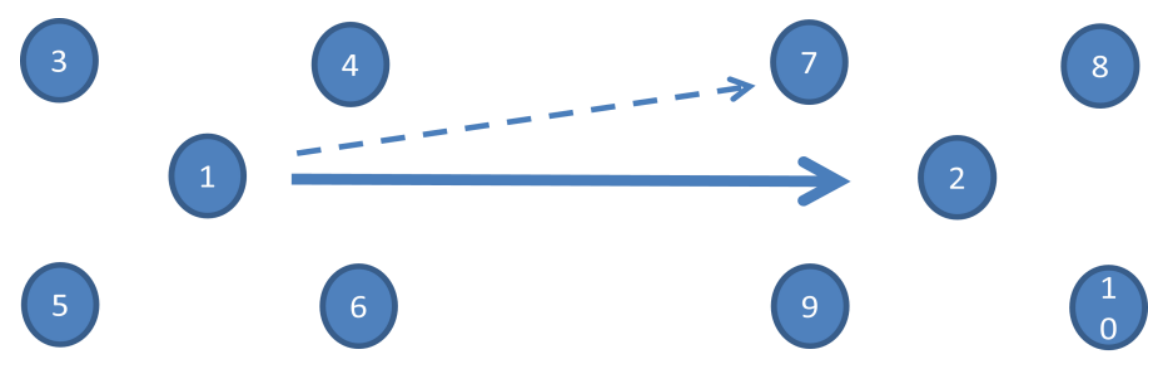

Source: MKmetric GmbH, 2014

Under consideration of this spatial competition Tij looks like:

$T_{12}=f\left(A_{12}, A_{17}, U_{12}, U_{17}\right)+v_{12}$

$T_{17}=f\left(A_{12}, A_{17}, U_{12}, U_{17}\right)+v_{17}$

Now all competing regions (below denoted with index $\mathrm{k}$ ) influence the attractiveness of the flow between $i$ and $j$, hence competition among regions is introduced which can lead to substitutive but as well to complementary effects in the choice of destination.

$T_{i j}=\rho T_{i k}+\beta\left(U_{i j}-\rho U_{i k}\right)+\omega_{i j}$

For more details about the spatial competition it is recommended to read the article 'Introducing Spatial Competition through an Autoregressive Contiguous Distributed (ARC-D) Process in Intercity Generation-Distribution Models within a Quasi-Direct Format (QDF)' available on www.mkm.de.

The next modelling steps concern the consumer's choice on transport mode, access / egress to / from the airport, airport and route as well as time slice in which the trip takes part. A mode choice model ${ }^{10}$ is used to identify the consumer's elasticities with respect to the alternative transport modes air, rail and road. Especially for countries / areas with a dense highway network and available high speed rail services the competition among modes is to be considered essentially. But this leads directly to the next choice problem of the consumer: How to approach the airport? Excellent high-speed rail connections from and to an airport increases the catchment area enormously allowing convenient access or egress. This influences the slot, airport and route choice as well which all together explain the consumers' selection of services and the competitive situation ${ }^{11}$.

While the first modelling step concerns the generation - distribution calculation allowing the construction of a matrix of traffic flows between the regions in focus, the second model level splits the amount of travellers detected between modes, access / egress options, airports, routes and time slices. Depending on the underlying data one can apply share or probabilistic models whereby the estimation algorithms differ but the principle

10. Schnellverkehr und Modal Split - High Speed Transport and Modal Split, Baden Baden:Nomos Verlag; Mandel

11. Airport Choice \& Competition - a Strategic Approach, Mandel B.; 3rd Air Transport Research Group (ATRG) Conference; Hong Kong 
remains the same. In the following the principle is outlined by using a share model, which is based on aggregated observations for the mode choice problem.

The share of travellers using mode $m$ on relation $i j$ (denoted as $t=1, \ldots, i, \ldots, I$ ) is equal to the attractiveness $v$ of mode $m$ on relation $t$ in context of the sum attractiveness of all modes $p(p=1, \ldots, M)$ on relation $t$. So it is just the relative attractiveness of one mode in respect to the one of all potential available modes. This is expressed by:

$$
\operatorname{sh}(m)_{t}=\frac{e^{v_{m_{t}}}}{\sum_{p=1}^{M} e^{v_{p_{t}}}} \text { with } \quad v_{m_{i}}=\beta_{0_{m}}+\sum_{n} \beta_{n} N_{n_{i}}^{\left(\lambda_{x_{n}}\right)}+\sum_{a} \beta_{a} S_{a_{i}}+\sum_{p} \beta_{p} P_{p_{i}}
$$

whereby $\mathrm{N}$ are network characteristics, e.g. time, cost, frequency (where $\lambda$ indicates nonlinearity which is discussed later), $\mathrm{S}$ are socio-economic characteristics, e.g. age-class, gender, employment, household size, income and P are characteristics of the trip purpose, e.g. trip duration, business.

Alternatively probability models based on disaggregate observations can be formulated in the same way. The probability of an individual traveller $n$ choosing a mode $i$ is expressed as follows:

$$
P(i)_{n}=\frac{U_{i n}}{\sum_{j} U_{j n}} i, j \in C_{n} \quad \text { with } U_{i n}=e^{\left(\beta_{i} x_{i}+\sum_{k=1}^{K} \beta_{k i} x_{k i n}\right)}
$$

where $U$ is expressing the utility of the mode $n$ experienced by individual $i$ or $j$ (denoted as $\mathrm{m}$ ) and $\mathrm{X}$ refers to the $\mathrm{N}, \mathrm{S}$ and $\mathrm{P}$ characteristics stated above. Both forms are of simple logistic form reflecting the proportion of one alternative to all others, whereby the dependent variable is given by an observed share of demand an alternative attracted or alternatively the dependent variable is an individual decision of a consumer for an alternative out of a set of alternatives. The latter usually is extracted from an individual survey.

Assuming observations, samples and all other necessary input data are perfect so that the models fulfil all criteria mentioned before, it is essential to know what type of functional form the models use. Analysis based upon observations drawn from travel surveys and traffic counting show that consumer do not behave linear. First they tend to reverse their decision according to changes in the attractiveness of an alternative (e.g. the reduction of a trip duration by 30 minutes will have larger effects on short haul routes than of long haul routes as it makes a proportional higher difference to travel one hour instead of $1: 30 \mathrm{~h}$ in comparison to travel $7 \mathrm{~h}$ instead of 7:30 h) and second they are as well inelastic to a certain extent (e.g. one day return trip above $600 \mathrm{~km}$ distance requires air mode and the reverse some people fear to fly).

To encounter these behavioural issues the mathematical form of a model has to allow for adjustments of the curvature measured on the base of observations. Such additional degrees of freedom must be estimated simultaneously so that each characteristic describing an alternative is weighted correctly in relationship to all other characteristics to reflect the balance of its influence upon the traveller properly. The degrees of freedom 
mentioned concern the non-linearity and the captivity of the functional form. To explain their importance two simple interpretations out of daily live are provided in the following.

People with a certain low monthly budget could not afford to travel by air 10 years ago, but today with low cost offers from LCC's and legacy carriers they can, so a certain threshold was passed and those people started to travel by air. Another example concerns the saturation effect captured as well by captivity as people have a certain time budget available for trips which cannot be extended, e.g. limitation of vacation time, even if interesting offers are available at the market. Thus consumer's elasticity is a key issue to understand when forecasting.

The models shown above imply a linear functional form. In consequence the effect of a given difference in transport conditions is independent of the service level characteristics so that the response curve to changes in service characteristics is symmetric with respect to its inflection point. But as outlined the traveller's behaviour is non-linear. Thresholds influence the decision and activate changes in product choice.

Therefore the functional form must be flexible so that one can circumvent linearity in variables and consider the level of the variable. To introduce the non-linearity different possibilities exist. E.g. the Box-Cox transformation can be applied for strictly positive variables:

$B C: x^{(\lambda)}=\left\{\begin{array}{crr}\left(x^{\lambda_{k}}-1\right) / \lambda_{k} & \text { for } \begin{array}{l}\lambda_{k} \neq 0 \\ \ln (x)\end{array} & \lambda_{k}=0\end{array}\right.$

The BC transformation applied on the probability model leads to the following form:

$$
P(i)_{n}=\frac{e^{\left(\beta_{i} x_{i}+\sum_{k=1}^{K} \beta_{k i} x_{k i n}^{(\lambda)}\right)}}{\sum_{j} e^{\left(\beta_{j} x_{j}+\sum_{k=1}^{K} \beta_{k j} x_{k j n}^{(\lambda)}\right)}}
$$

The following figure shows the different curvatures of the linear Logit function and the ones with transformations applied on a positive variable ${ }^{12}$. The range of thresholds is with the asymmetric tail of the function and indicates the change of travel time where people start to reconsider their behaviour over-proportionally.

When looking at the linear and BC-Logit curvature it has to be noted that the choice probabilities go to zero (one) when the representative utility $V_{i}$ goes to $-\infty(+\infty)$ so that (see figure above) one cannot model thick tails due to specification error, modeller ignorance, compulsive consumption or captivity to alternatives. To bypass this constraint, the captivity of consumers, the Box-Tukey transformation can be used:

12. Linear or Non-linear Utility Functions in Logit Models? The Impact on German High Speed Rail Demand Forecasts; Transportation Research Journal Vol. 28B; Elsevier Science Ltd; Mandel B., Gaudry M., Rothengatter W.; 1994 
$B T: \quad x^{(\lambda, \mu)}=\left\{\begin{array}{cr}\left(\left(x_{k}-\mu_{k}\right)^{\lambda_{k}}-1\right) / \lambda_{k} \\ \ln \left(x_{k}+\mu_{k}\right)\end{array}\right.$ with $\begin{array}{l}\lambda_{k} \neq 0,\left(x_{k}+\mu_{k}\right)>0 \\ \lambda_{k}=0,\left(x_{k}+\mu_{k}\right)>0\end{array}$

The BT transformation applied on the probability model leads to the following form:

$$
P(i)_{n}=\frac{e^{\left(\beta_{i} x_{i}+\sum_{k=1}^{K} \beta_{k i} x_{k i n}^{\left(\lambda_{k i}, \mu_{k i}\right)}\right)}}{\sum_{j} e^{\left(\beta_{j} x_{j}+\sum_{k=1}^{K} \beta_{k j} x_{k j n}^{\left(\lambda_{k j}, \mu_{k j}\right)}\right)}}
$$

In the figure below it can be seen that there are about $20 \%$ inelastic captive riders who are forced to use the displayed alternative irrespective of any changes in the variable, e.g. long-haul business travellers. The $\mu$ coefficient allows the function to converge to a certain level at both sides of the function.

Figure 4. Functional forms

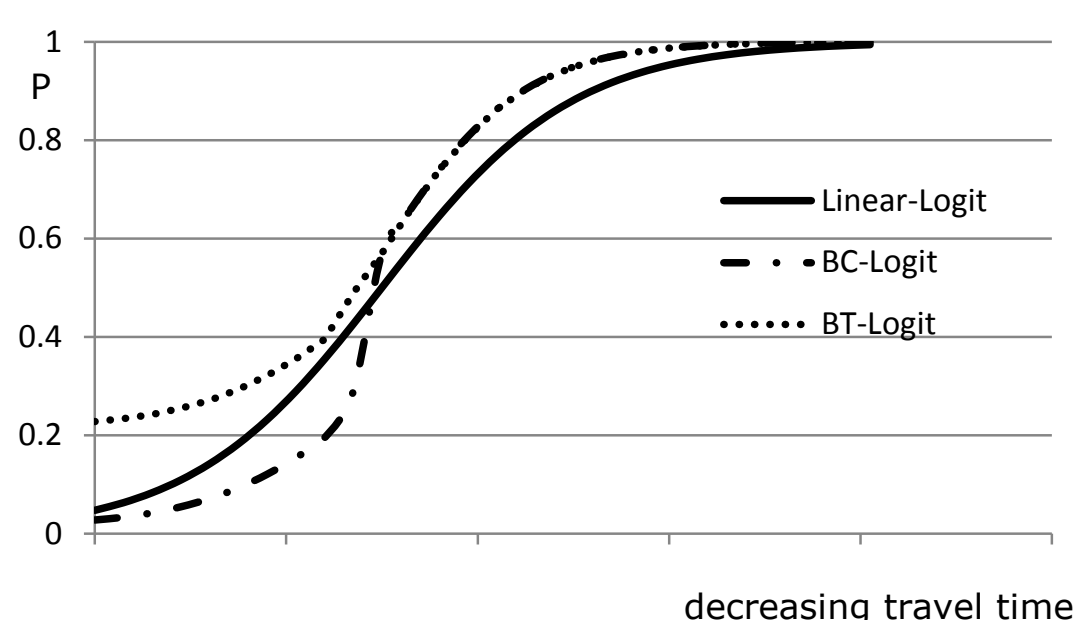

Source: MKmetric GmbH, 2014

A linear functional form which considers captivities is available when choosing the Dogit model. But also a Box-Cox transformation can be applied in parallel. This allows catching captive riders in combination with non-linearity of variables. This form looks as follows:

$$
P(i)_{n}=\frac{e^{\left(\beta_{i} x_{i}+\sum_{k=1}^{K} \beta_{k i k i n} x_{k i}^{\left(\lambda_{k i}\right)}\right)}+\theta_{i n} \sum_{j} e^{\left(\beta_{j} x_{j}+\sum_{k=1}^{K} \beta_{k j} x_{k j n}^{(\lambda)}\right)}}{\left(1+\sum_{j} \theta_{j n}\right) \sum_{j} e^{\left(\beta_{j} x_{j}+\sum_{k=1}^{K} \beta_{k j} x_{k j n}^{(\lambda)}\right)}}
$$


Within the system approach outlined the technique of choice modelling described is used for all the choice problems mentioned.

Up to now the models are independent from each other and to encounter the effects from one decision level respectively model level to the other one has to link the modelling steps by the quasi-direct format (QDF) ${ }^{13}$ using the representative utility function of the lower level models in the upper ones as an additional independent explanatory variable, which is called modal utility index. This link ensures consistency of behaviour across the system approach.

As example the quasi direct format is explained for the generation-distribution model which includes the modal utility index, respectively denominator, of the modal split model as an independent characteristic in the mathematical expression of the problem in focus.

$$
Q D F: T_{i j}^{m}=T_{i j} \cdot S_{i j}^{m}=T_{i j} \cdot \sum_{j} e^{\left(\beta_{j} x_{j}+\sum_{k=1}^{K} \beta_{k j} x_{k j n}^{\left(\lambda_{k j}\right)}\right)}
$$

The linkage of the model levels is as well a prerequisite for the reflection of the interdependencies within the decision process of a consumer ${ }^{14}$. This may concern the relationship of the consumer's choice and travel demand as well as the one concerning the competition of modes (multi-modality - rail-road-air-sea), the co-operation of modes (inter-modality - transport chains across modes like rail \& fly, sea-road) and the competition within a transport mode system (intra-modality - e.g. selection of different routes including various transfer hubs and airports at the origin and destination). As example it is referred to the establishment of high speed rail services like the TGV which reduced the air traffic significantly between Paris and Lyon, Brussels or Strasbourg (multi-modal effect).

On the other side the establishment of a new high speed rail service station at an airport like in Frankfurt resulted in a huge extension of the catchment area (intra-modal effect) and substituted short haul flights (inter-modal effects). In the light that consumers always try to maximise their utility and do not follow a static behaviour such effects have to be considered to draw a realistic picture of the transport system and the effects which occur when taking strategic, tactic and operational decisions.

Another aspect addressed concerns the traveller's elasticity. For all expressions one can derive this measure such as the point elasticity:

$$
\eta\left(S(i)_{n}, x_{k i n}\right)=\frac{\partial S(i)_{n}}{\partial x_{k i n}} \frac{x_{k i n}}{S(i)_{n}}
$$

13. Methodological Developments within the Quasi-Direct Format Demand Structure: the Multicountry Application for Passengers MAP-1; Strategic European Multi-Modal Modelling Gaudry M., Heinitz F., Last J., Mandel B.; Working Paper BETA n॰9815

14. The Interdependency of Airport Choice and Travel Demand; Taking stock of air liberalization, Proceedings of the International Symposium at the ICAO; Kluwer Academic Press; Mandel B. 
It is just the derivation of the function for a certain variable. As a result a ceteris paribus variation of the demand for alternative $i$ by a $1 \%$ change of the characteristic value of alternative i can be computed. So market effects can be analysed when changing supply characteristics, e.g. reducing the price of an alternative, increasing the service frequency or introducing a new service.

In principle the whole system approach can be expressed as a function of elasticities, such as:

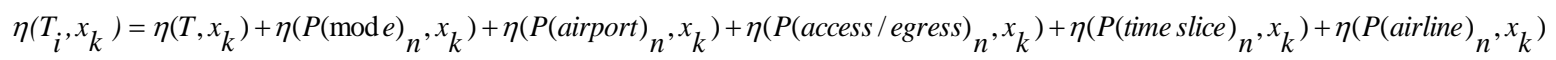

or in simplified notification:

$\eta($ alternative $)=\eta($ total flow $)+\eta(\bmod e)+\eta($ airport $)+\eta($ access $/$ egress $)+\eta($ time slice $)+\eta($ airline $)$

With this set of elasticities all kind of competition within the transport system is measurable ${ }^{15}$ as the model set is interpreted as a cascade of elasticities.

Last but not least, procedures are required to compute impedances which reflect the attractiveness of each alternative based on the infrastructure networks of all modes. The different algorithms used cope with the specifics of the modes. Assuming the granulation level of schedules for air transport connection builder have to be used which consider flights, airlines, alliances, code shares, time zones and connecting times at airports as well as access/egress time. It is recommended to develop a tailor made procedure to optimise the algorithm so that it can cope with the problem addressed in harmony with the available computer processing power, whereby parallel processing should be kept in mind to minimize run time. The impedances computed need to contain the network path information to allow an assignment of the traffic demand.

Please note that the methodological description provided just sheds a light upon the principles of the system approach and it is recommended to have a look at the publications mentioned which can be withdrawn from the following web site: www.mkm.de section publications/papers.

To complete the picture it is obvious that once the demand forecast is executed aircraft movements differentiated by e.g. 8 MTOW classes and schedule or peak day analyses can be derived. For air cargo an equivalent approach is developed.

\subsection{Reflection of the status quo as reference point \& scenario simulation}

The analysis of the forecast can base on an ex post or either an ex ante scenario. While the basic framework data of a reference year for an ex post analysis are available from national statistical offices or published commercial sources like schedules respectively, the data for an ex ante scenario have to be worked out for the specific year to be forecasted.

The ex post forecasts can be used in two ways. First of all the representation of a given reference year is important to validate the systems output in front of the reality, say measured observations like statistics. This exercise is envisaged by a matrix bounding

15. Measuring Competition in Air Transport; Airports and Air Traffic - Regulation, Privatisation and Competition Hamburg, Germany, HWWA; Peter Lang Press; Mandel B. 
approach and has to be executed always at first when setting up the system for a project to ensure a high quality of results. The principle procedure is depicted in the following figure.

The calibration is an iterative process where data from various sources and model results are assessed to detect irregularities, inconsistencies and errors. The arrows symbolise the principle process flow, while the recursive parts and their nesting are not displayed due to their complexity.

Let's assume a model set is available as well as all the necessary input data to complete a run (see the blue coloured boxes in the following figure). As result of a ceteris paribus model run for the reference year one receives an ex post forecast. These model results are validated by independent data sources like national statistics, link counts, surveys, etc. to identify irregularities, inconsistencies and errors. They are investigated by checking input data, procedures, programmes and models whereby errors are corrected - in the worst case even by setting up new model estimations. This step is essential to make sure that model results are reflecting reality at an objective reference case or a base year respectively. This allows enhancing market transparency and displaying a full market picture of a previous year, to benchmark demand effects which can be investigated as ex post forecast as it is crucial to understand the competitive situation stakeholders are in.

Figure 5. Validation, calibration and simulation

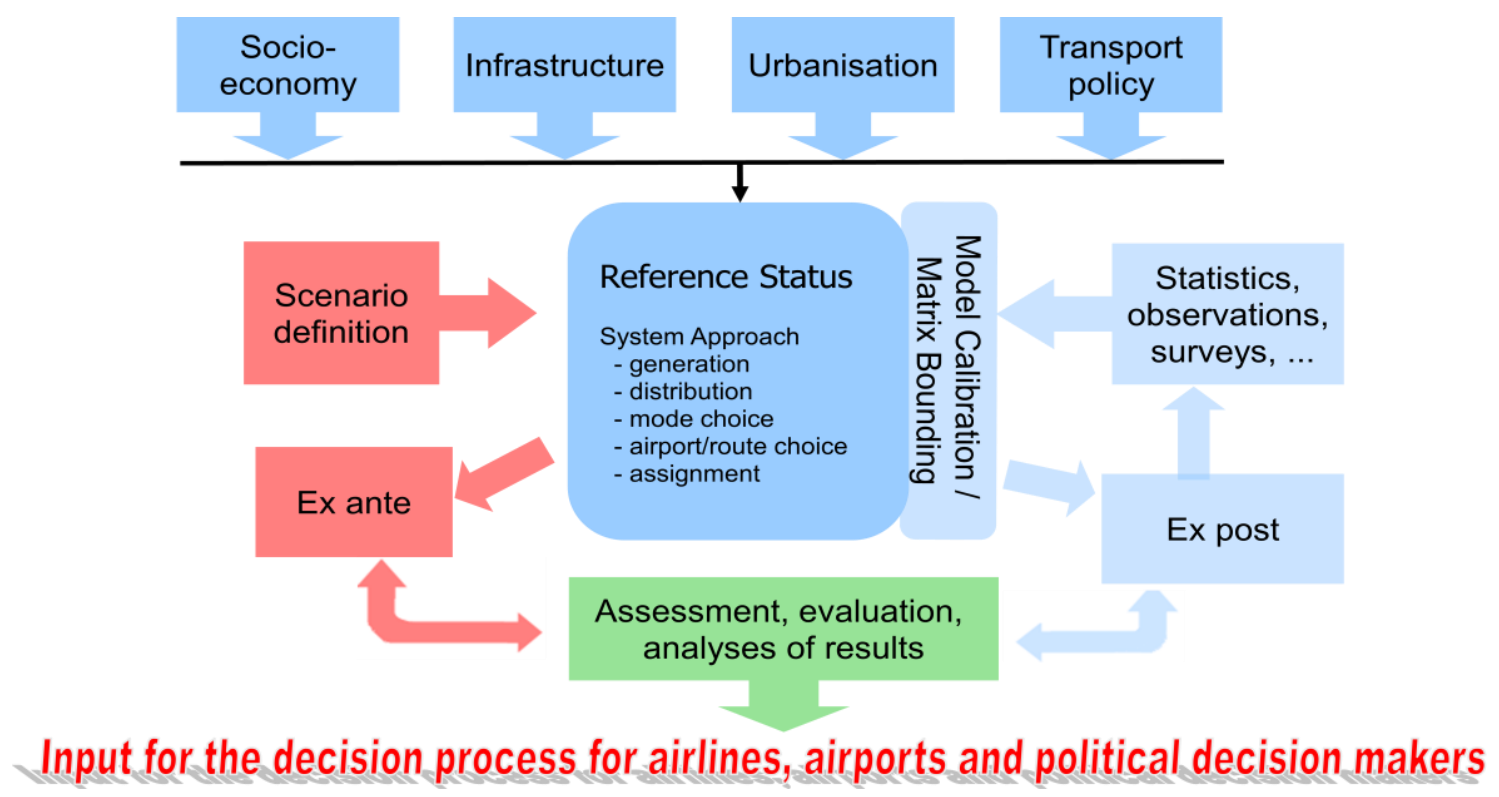

Source: MKmetric GmbH, 2014

The second possibility of ex post forecasting can be used to answer the question: 'What would have been the effects, if a certain determinant of transport would have been changed?' So without any bios, due to uncertainties every assumption of future developments have, one can investigate transport policy actions or strategic respectively tactical changes of the market participants.

In addition market potentials of new routes can be investigated under ceteris paribus conditions of the existing market. A successive scan of new air services (SONAR) 
identifies, evaluates, and ranks all technically possible routes from a defined airport. It takes into account the offers of all competing airports and their catchment areas. The procedure SONAR implements the best identified routes in the simulation system and integrates them into an actual flight schedule. Finally, the passenger potential is calculated. The system allows optimising the existing flight services, if passenger potential is not yet being fully exploited. Interdependencies between new and existing services in the air transport system as a whole are fully considered. As a result, one gets the most profitable routes for a certain airport. In case a network shall be optimised or if routes shall be identified for a specific fleet of aircrafts the same approach can be used, just the internal routines need to be arranged differently as the principle remains valid.

The ex ante forecasts allow a wide range of scenario simulations. Any change of the transport determinants described within the framework conditions can be applied and will lead to effects. Whether one or several of determinants change does not matter for the system approach as all influencing factors will interact consistently according to the linkage of all econometric models engaged. Therefore a scenario can consider the effects of e.g. implementation of kerosene tax, the establishment of a new airport, the installation of new high speed rail services and a change of the home base carrier's network strategy at the same time. Obviously network dynamics as well as more complex socio-economic interrelations are covered across all modes, such as the effects of regional differences in purchase power or geo-metrics and the interrelationship of mobility and oil price.

For the different model stages below some examples of scenario elements are listed:

$>$ Generation - distribution of traffic:

- Socio-economic framework data (e.g. population, trade, GDP, oil)

- Political decisions (e.g. taxes, security, noise charges)

- Regional attractiveness (e.g. type of region, temperature, sea, mountains)

- Political decisions (e.g. traffic rights, subsidies)

$>$ Mode choice:

- Network/Service characteristics (e.g. time, cost, frequency, transfer, operation days)

- Political decisions (e.g. public service obligation (PSO), infrastructure investments)

$>$ Airport / Route choice:

- Service-Structure (e.g. new route / closure, minimum connecting times (MCT), airline base, transfer node)

- Infrastructure (e.g. access / egress by surface modes, inter-modal routes)

$>$ Assignment:

- Infrastructure networks (e.g. new airports, new high speed rail (HSR) services) and/or changes of network attributes (e.g. capacity, speed, charges, tolls, fees) 
Finally it has to be noted that the approach outlined is not just focused on one airport, in principle scenarios can cover multiple airports and in consequence considers the interdependencies evoking.

\subsection{Complexity and coverage}

To reflect a realistic picture of the transport activities it is necessary to mirror the situation a consumer is facing to a maximum extent. Therefore the starting point concerns the location of the travellers, respectively the place they live and the place they want to go to as usually people neither life nor make vacation at an airport, they just use transport systems to overcome the distance between two locations e.g. their home or office as origin and the destination beach or a business place in focus. In respect of this principle the transport flows have to be modelled from door to door respectively region to region.

The system approach installed uses the NUTS 3 level $^{16}$ (nomenclature of territorial units for statistics) for the European member states as representation of the travellers location, while the rest of the world is reflected by larger zones based on administrative boundaries on NUTS 2, 1 or 0 level (in total about 2300 regions). The implemented system approach concentrates therefore upon all traffic within, to, from and across Europe.

For the example of the air mode figure 1 in chapter 1.2 shows the difference of the conventional static approach and the more complex dynamic network approach we follow. In consequence of the regionalisation all the mode specific networks have to be compatible with this level of detail. So the road network consists of links down to the third order of streets (ca. 2.8 Mio. links) and the rail network considers rail services according to the published schedules reflecting different service types. The air mode considers within Europe all airports with published services based on HAFAS ${ }^{17}$ plus more than 200 representative airports for the rest of the world. Of course the air services are reflected as published in the schedules but need to be enriched by charter services or LCC services which are not covered by the commercial schedule providers. The underlying demand data framework must be representative and highly valuable for all commercial traffic.

To cope with intra-modality especially when considering competing hubs respectively alliances the route and airport choice models must consider at least 16 intercontinental and 10 continental alternatives. Only in combination of detailed regionalisation and detailed network representation a model is flexible enough to deal with the network dynamics of the transport market. Thus results of the system approach are dynamic, e.g. the catchment of an airport depends on the air services offered at all competing airports and can be different for each route and passenger segment (resp. trip purpose).

16. http://epp.eurostat.ec.europa.eu/portal/page/portal/nuts_nomenclature/introduction

17. http://www.hacon.de/hafas-en 


\section{APPLICATION}

In this section some analyses are highlighted which point out the capabilities of the existing tool of MKmetric using the modal approach as described in the previous sections, with special focus on airport and route choice. They all base on the status quo situation of air transport as existing in the year 2012.

\subsection{Airport choice}

The nucleus of the model is the airport choice of the consumer reflecting consumers' behaviour. For the trip from one distinct region to another the passenger has to decide which travel alternatives he chooses. This decision bases on individual weighting of the attributes applying for each travel alternative. In the model this weighting results in the calculation of choice probabilities assigned to the distinct route alternatives.

The following figure displays the sixteen travel options available within the simulation model between the city of Bremen, Germany, and the centre region of Thailand, around Bangkok and the choice probabilities on them for non-business-travellers.

Seven of the route alternatives start from the nearest airport Bremen (BRE) to the region of origin. As there are no direct flights between BRE and BKK, they all consist of flight options including a plane transfer at one hub, from which flights to BRE as well as to BKK are provided, namely Amsterdam (AMS), Paris (CDG), Frankfurt (FRA), Istanbul (IST), Munich (MUC) and Zurich (ZRH), of which the one via FRA is the mostly chosen $(17.2 \%)$.

In addition there are also travel options available from other airports: Düsseldorf (DUS), Hamburg (HAM) and Hannover (HAJ), from which a flight to Bangkok is possible nonstop (from DUS and FRA) or via Hubs to which no flights from BRE are offered, e.g. like those from the Gulf carriers Etihad at Abu Dhabi (AUH) or Emirates at Dubai (DXB). From all these options the share of the one to go by surface transport to FRA and take a nonstop flight to BKK from there has the second largest share in this market $(14 \%)$, a result of the excellent accessibility of Frankfurt airport by high speed rail. 


\section{Figure 6. Airport choice for a trip from Bremen to Bangkok}

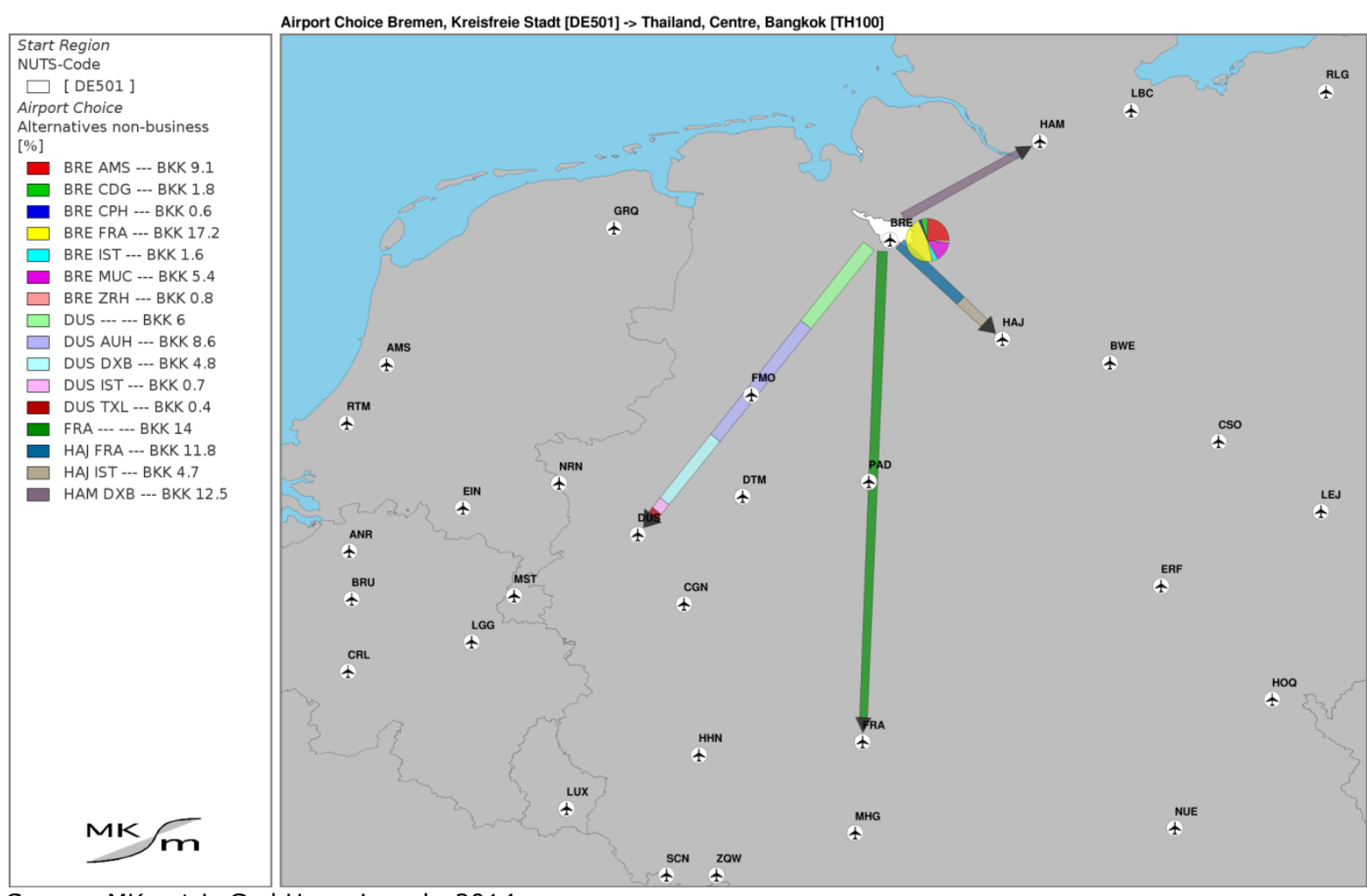

Source: MKmetric GmbH, x-via web, 2014

\subsection{Route competitors}

Similar to the airport choice analysis as mentioned before, this example displays the different routes which compete for a distinct OD-market. As input for the analysis we have chosen the airports of Sao Paulo (GRU), Brazil and Tokyo Narita (NRT), Japan and a limitation of the catchment area of both airports by 120 minutes of access / egress time.

The figure displays the most relevant route chosen between those regions, from which the airports mentioned can be reached within 2 hours by surface transport. The routes are coloured in line with the number of passengers travelling on each of them. The routes considered not necessarily do all link the airports of GRU and NRT.

As GRU and NRT are more or less antipodes to each other (greater circle distance is at about $18500 \mathrm{~km}$ ), there are eastbound as well as westbound travel options.

The westbound travel-options displayed, which in this case take the core of demand are all with a plane change at an US-airport. The route via Dallas Fort Worth (DFW) is the most important of them, attracting more than 40,000 passengers, while the others, e.g. via New York's John F. Kennedy Airport (JFK), Chicago (ORD), Newark (EWR) or Washington (IAD), have smaller shares on the total demand $(\approx 100,000$ passengers as sum of both directions). Minor passenger flows (not displayed) on this OD-pair occur via San Francisco, Houston and Toronto, Canada.

In the eastbound direction, the routes from GRU via the European airports Paris (CDG), Frankfurt (FRA), Munich (MUC) and Rome (FCO) to Tokyo are the most relevant travel 
options. While most of them are heading to Tokyo's Narita airport (NRT), there is also a second option when travelling via CDG: instead of flying to Narita, via Paris it has also been possible to travel to/from Tokyo's Haneda Airport (HND), from which in 2012 direct flights to Paris existed.

Figure 7. Route competitors for the route GRU - NRT

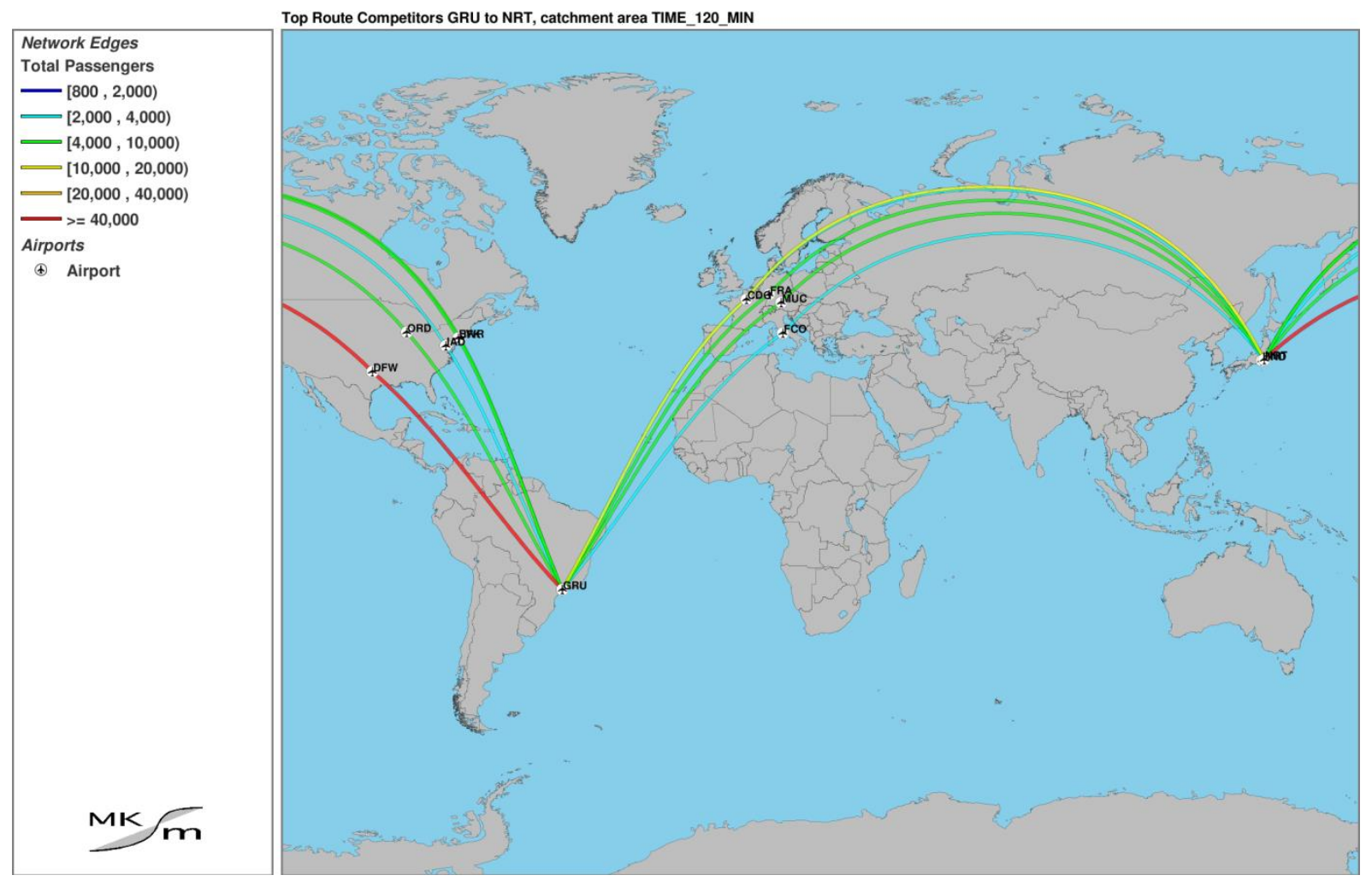

Source: MKmetric GmbH, x-via web, 2014

\subsection{Flight segments}

After calculating all routes choices for every pair of origin/destination regions and enriching them with the underlying passenger flows on regional base it is possible assigning them either to distinct flight segments or in case of transfer connections to sequences of them. One possible analysis of such an assigned air network is to depict a specific flight segment and point out how many travellers use it, either as nonstop flight or also as part of a flight connection. Just imagine you are sitting in a plane and interview all passengers on board from where they come and to where they are travelling. The result of such an "interview" on a flight between Hamburg (HAM) and Dubai (DXB) is displayed in the following picture. While the number of passengers, which entered at HAM from another flight, is minimal, a vast majority of passengers originally starting to fly from HAM, do not have their final destination at DXB, but transfer there for other destinations, either in the Middle East, in South-East Asia, Oceania or in Eastern and Southern part of Africa. Also those passengers, travelling between the city of Bremen and the Thailand, centre, we had identified in the airport choice analysis, are part of the passenger volumes displayed below.

It should be mentioned that this type of analysis is not only feasible for existing routes, furthermore it can be used to identify the acquirable demand for new routes to be 
implemented into an existing air network and point out the routes' passenger potential concerning local traffic as well as the number of transfer passengers who would use a new route.

Figure 8. Passenger diversity on the flight segment HAM - DXB

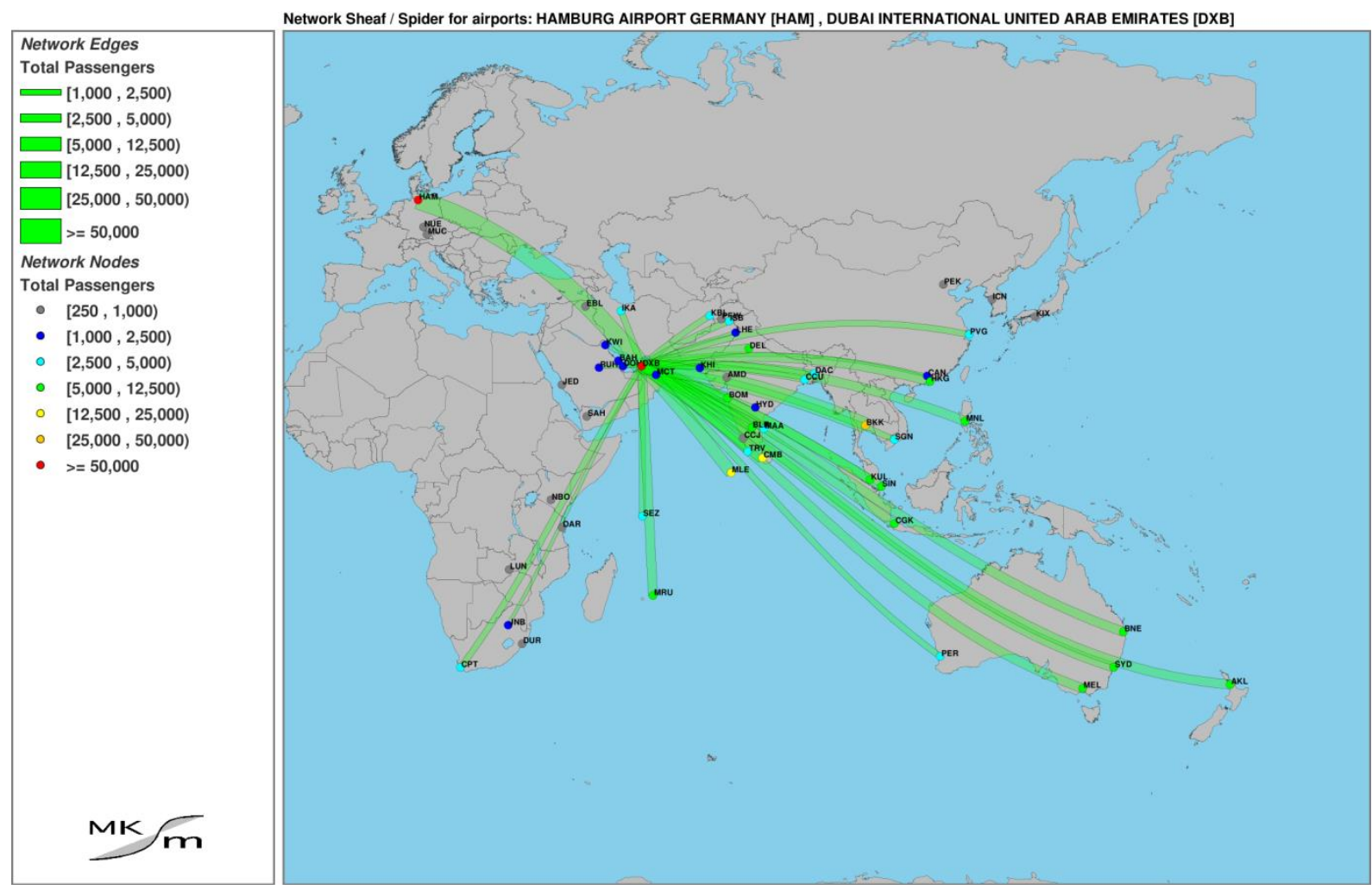

Source: MKmetric GmbH, x-via web, 2014

\subsection{Demand sensitivity to slots}

Routes to or from a hub or also connecting to hubs provide multiple transfer option on one or both of the airports connected. The amount of transfer options available and their attractiveness for the consumer depends on the transfer time between the flights and the frequency such transfer options are provided. Long layovers or transfer options only rarely provided make competing routes more attractive. In addition, on an airlines point of view not only the absolute number of transfer passengers is in focus, but also their total travel distance is of importance, as the revenues received from an intercontinental passenger are higher than those from a short-haul passenger.

To cope with this needs an analysis has been developed, the 'weighted connectivity'. The weighted connectivity for a specific route takes into account all transfer options available for each distinct slot at one of the airports connected by the route, weighted by the duration between an arrival at this slot and the next available departure time for each different transfer destination. In addition each of these transfer options are weighted by the passenger potential from the considered routes' origin to each transfer destination. In the following pictures the analysis for the existing route between Seoul (ICN) and Prague (PRG), either for PRG and in the second picture for ICN is shown. 
Figure 9. Passenger demand sensitivity to the air service Seoul - Prague Weighted connectivity from/to ICN - SEOUL INCHEON INTERNATIONAL AIRPORT KOREA, REPUBLIC OF at PRG - PRAGUE CZECH REPUBLIC for connecting SKYTEAM flights

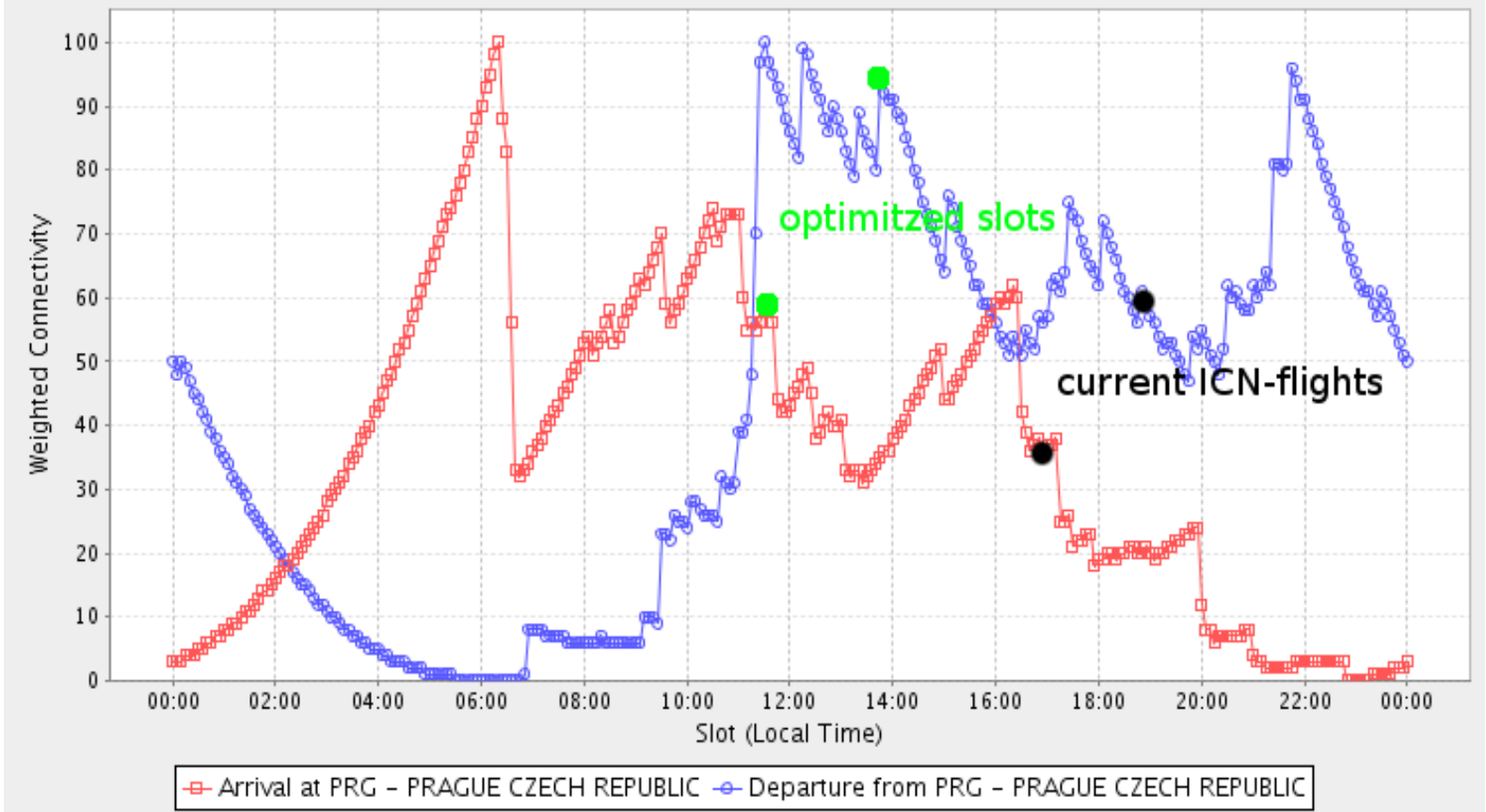

Arrival/departure from ICN at PRG versus demand

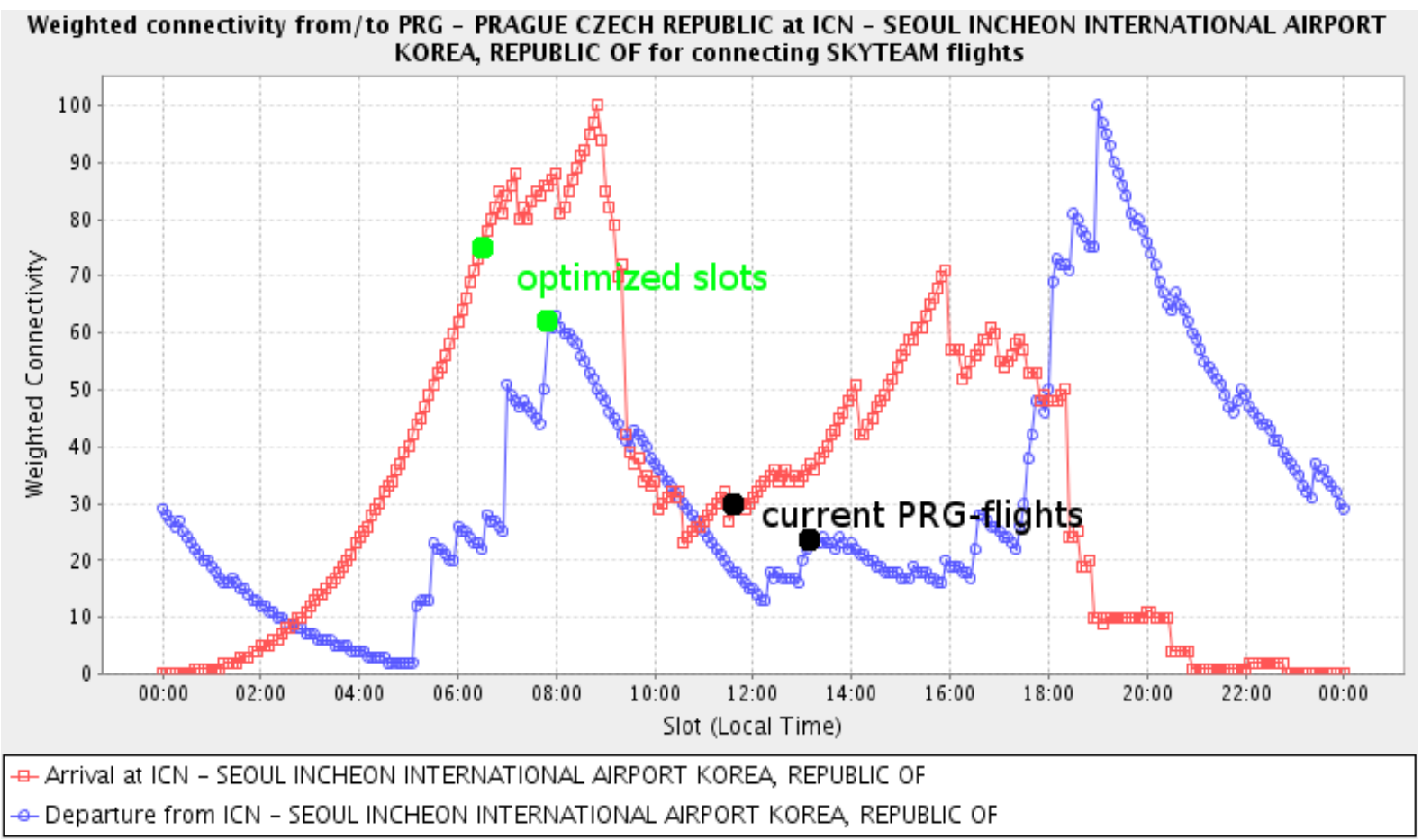

Arrival/departure from PRG at ICN versus demand

Source: MKmetric GmbH, x-via web, 2014 
This connectivity analysis neglects transfer options requiring a relevant detour relative to an existing nonstop flight option. For example when doing a weighted connectivity analysis for the route PRG-ICN, transfer options for Abu Dhabi (AUH) are neglected, as AUH is available nonstop from PRG as well as from ICN and flying from ICN via PRG to the Middle East (or even worse from PRG via ICN to AUH) would mean an enormous detour compared to the existing nonstop flights.

Also the minimum connecting times for the airports connected were taken into account. The values calculated are on an index base with a value of 100 for that arrival / departure slot offering a maximum of connectivity. These graphs shows vertically the weighted connectivity results of the pre-analysis for an air service for a distinct route whereby the red line depicts the arrival index at the mentioned airport while the blue line reflects the departure index along the horizontal timeline.

So when marking the current arrival / departure times for the route considered in PRG and as well in ICN (black spots), one can see that, the slots chosen do not provide the maximum connectivity possible at both airports (index values of 20/30 at ICN and 60/35 at PRG). But when operating the flights about four to five hours earlier, i.e. stop at PRG around lunch time instead of late afternoon and arrive/depart at ICN in the morning instead of midday, would lead to a significant higher connectivity for these flights, resulting in index values of 60/90 at PRG and 75/60 at ICN.

This analysis can also be used, as a pre-step procedure to identify an optimal schedule for a route to be examined in the simulation model.

\subsection{Dynamic catchment}

It was outlined in the airport choice section, that consumers may chose a starting airport which is quite distant form their region, if its accessibility is good and the flight options offered there (e.g. nonstop flights) are not available from the airport which is closest to their region with a significant probability. For the question of the size of an airports' catchment this means, that such a catchment can be defined neither by just drawing a circle in a distinct distance around this airport, nor that all regions within a specific isochrone "belong" to an airport exclusively, while other regions strictly can be assigned to other airports. To point this out, the catchment of an airport for two different destination markets is displayed and all regions from which an airport can attract passengers are coloured. 
Figure 10. Catchment of Frankfurt for destinations in the Far East

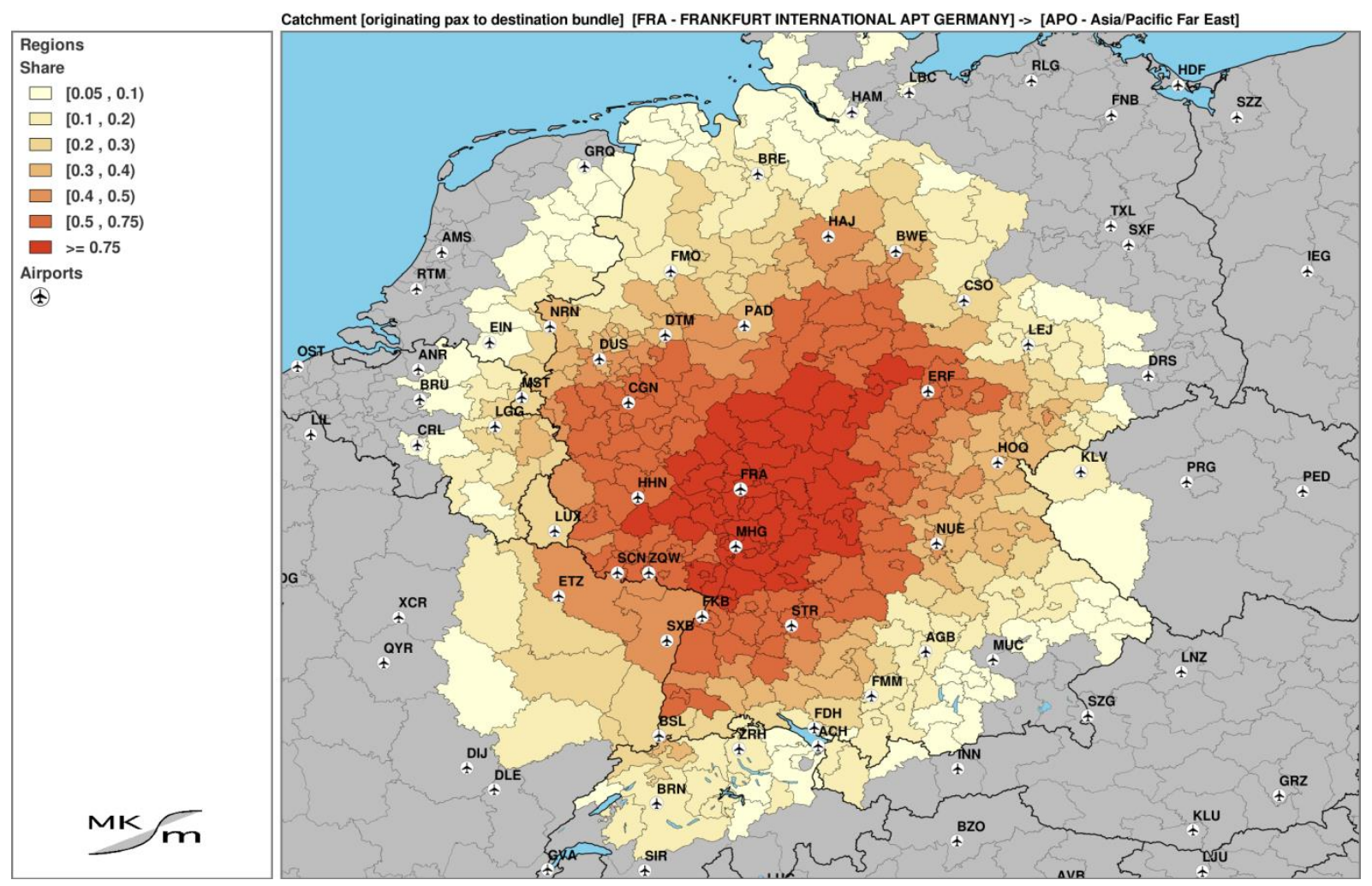

Source: MKmetric GmbH, x-via web, 2014

The different colours from yellow to red reflect the market share the airport considered has in the specific region. Market share in this context means: if an airport can attract 24 out of 100 passengers from a region, while the 76 others chose different airports to start their trip, the market share of the airport considered in this region is $24 \%$. Regions from which the airport can attract less than $5 \%$ of all passengers are displayed in grey.

In the figure above the catchment by market share for the airport of Frankfurt concerning destinations in the Far East is depicted. On base of regions where Frankfurt can achieve a market share of at least $5 \%$, the area stretches from the very North of Germany to Switzerland and the most Western part of Austria in the South, covering a distance of about 1,000 kilometres. In the East-West direction parts of the Netherlands, Belgium, France and Luxembourg belong to this catchment, which reaches in the east Saxony and even that part of the Czech Republic bordering to Germany - in total a distance of more than 600 kilometres is covered in this direction. The provision of nonstop flights to numerous destinations in the market considered, of which the most are not available from other airports in the close or larger vicinity of Frankfurt, with some of them even exclusively provided at Frankfurt for the European continent and the excellent connection of FRA with high speed rail services, are the reason for this huge catchment concerning the Far East market. 
Figure 11. Catchment of Frankfurt for destinations on the British Isles

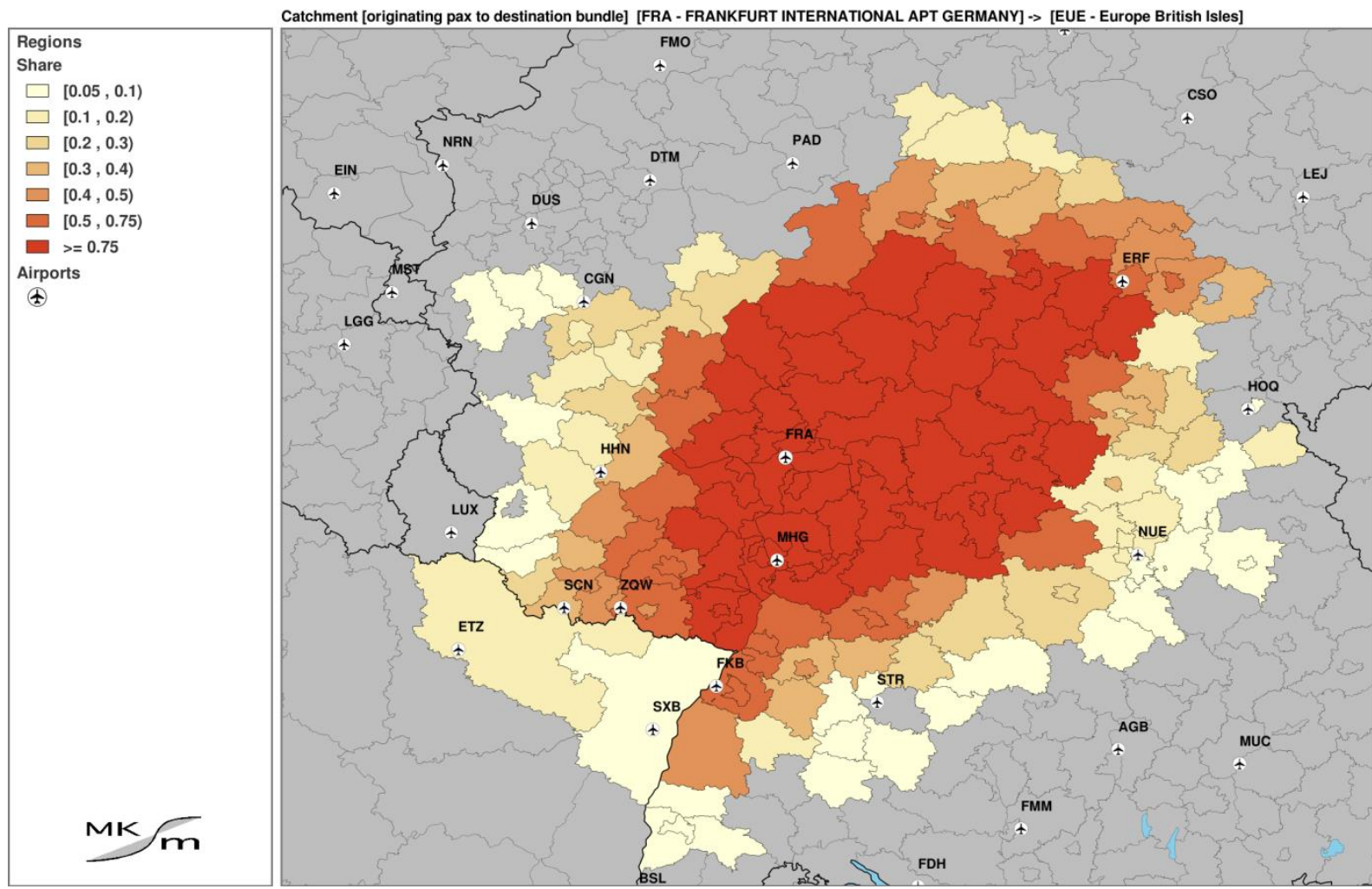

Source: MKmetric GmbH, x-via web, 2014

Different to that, the catchment of Frankfurt concerning destinations on the British Isles: By far smaller, just covering the centre regions of Germany plus some neighbouring départements in France, with a total extension between 300 and less than 500 kilometres. The reason for this in comparison quite small catchment is that the destination portfolio of most airports surrounding Frankfurt at least covers one of the London airports and in many cases also quite a few other destinations in the UK or in Ireland.

Such analyses allow an airport to identify quite well, where its core markets are or where it might be worthwhile to put more marketing efforts, but it gives no answers in which regions a distinct other airport is a serious competitor. To answer such type of questions it is useful to display simultaneously the catchment areas of two different (competing) airports in one graph. As example this analysis is displayed for the two airports of Geneva (GVA), Switzerland and Lyon (LYS), France, both with quite a few international and even a limited number of intercontinental flights in their destination portfolios. Regions where LYS has a strong market position are coloured in red, those where GVA dominates come in green and all regions where other airports can acquire the core of demand, but from which at least minimal passenger numbers use one of the two considered airports are in blue. Regions where market domination is with none of the considered airports or their competitors are with mixed colours. For example the RhôneAlpes area directly between GVA and LYS which is in yellow and heavily competed between the two airports considered. 
The figure shows the market domination of GVA, which not only covers the Northern part of the Lac Léman area, but also the French regions in South of Geneva, which are famous Ski resorts, while the focus of LYS, beside the city of Lyon, more lies in the South of LYS down to Avignon, from where the influence of the Marseille airport (MRS) dominates the market.

\section{Figure 12. Competition between Lyon and Geneva for originating passengers}

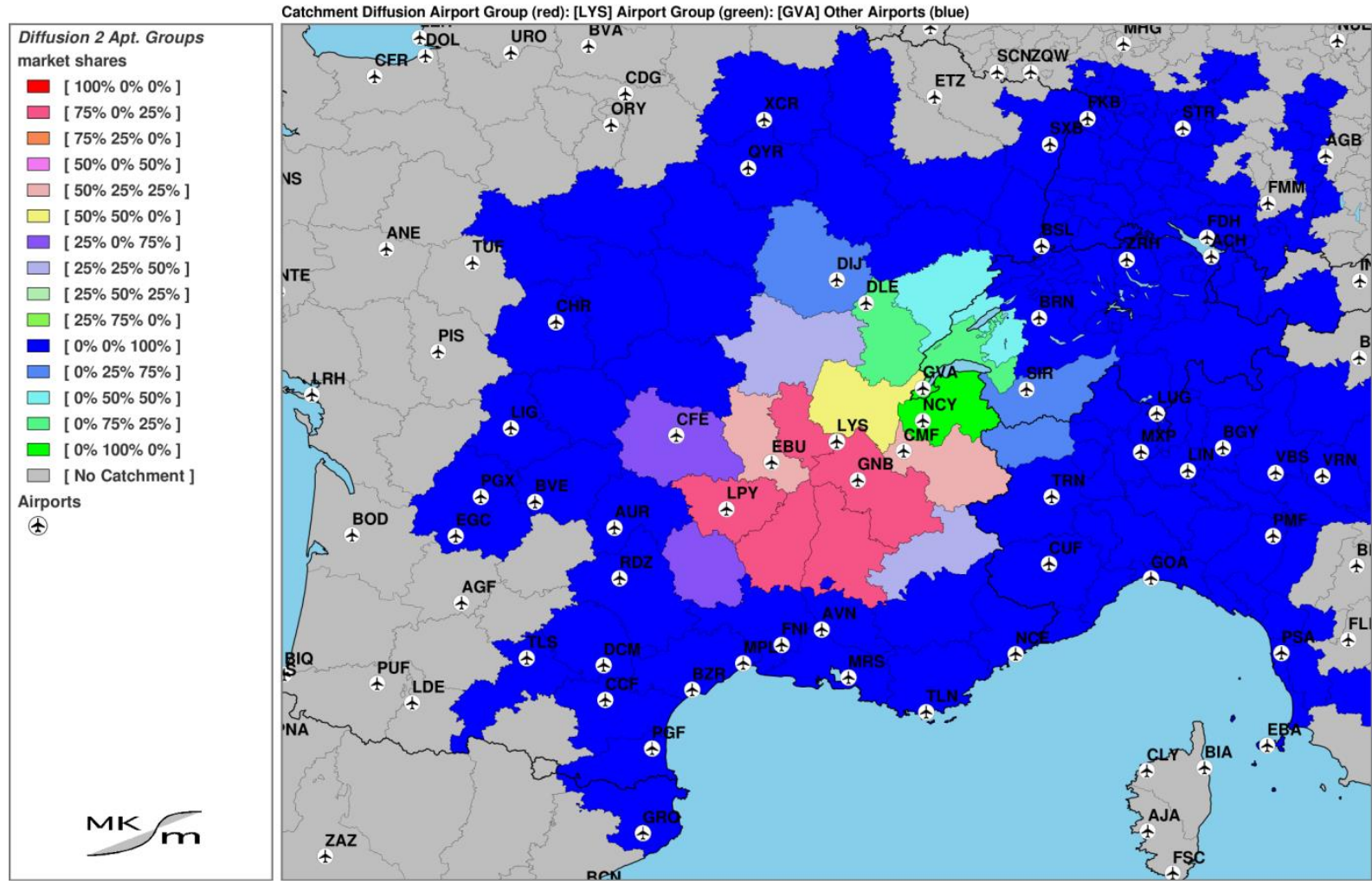

Source: MKmetric GmbH, x-via web, 2014

\subsection{Long-term forecast}

Finally it should be mentioned that modelling air transport as described in the previous chapters is not limited for status quo analyses or short term estimations on passenger potentials for new routes, but also can be used for long term forecasts, as executed for example in the early 90's for the airport system of Berlin with a long term forecast for the year 2010.

Within this long-term forecast

- the political framework,

- the planned development of surface transport infrastructure

- the network development according to demand for the Berlin airports as well as for their competitors

had been considered. 
Covering all those aspects led - from today's' point of view - to a quite realistic estimation of the passenger demand until 2010, although it should be mentioned that at the time of forecasting (1993) the identified demand for Berlin of 23 million passengers in 2010, was criticised, as several other forecasts with standard models promoted much higher passenger volumes for Berlin, reaching in maximum up to 60 million passengers. These optimistic forecasts resulted out of enthusiastic assumptions blinded by the development of the first booming years after German reunification concerning the trends in passenger figures at the Berlin airports and economic development of the city, while neglecting any long term effects on modal split by new built or upgraded railway lines, the strategies of leading European network carriers, the development in air transport in neighbouring Poland and many other components of serious forecasting which were not considered adequately.

Figure 13. Long term forecast Berlin (1993 to 2010)

BER - Forecast and Development

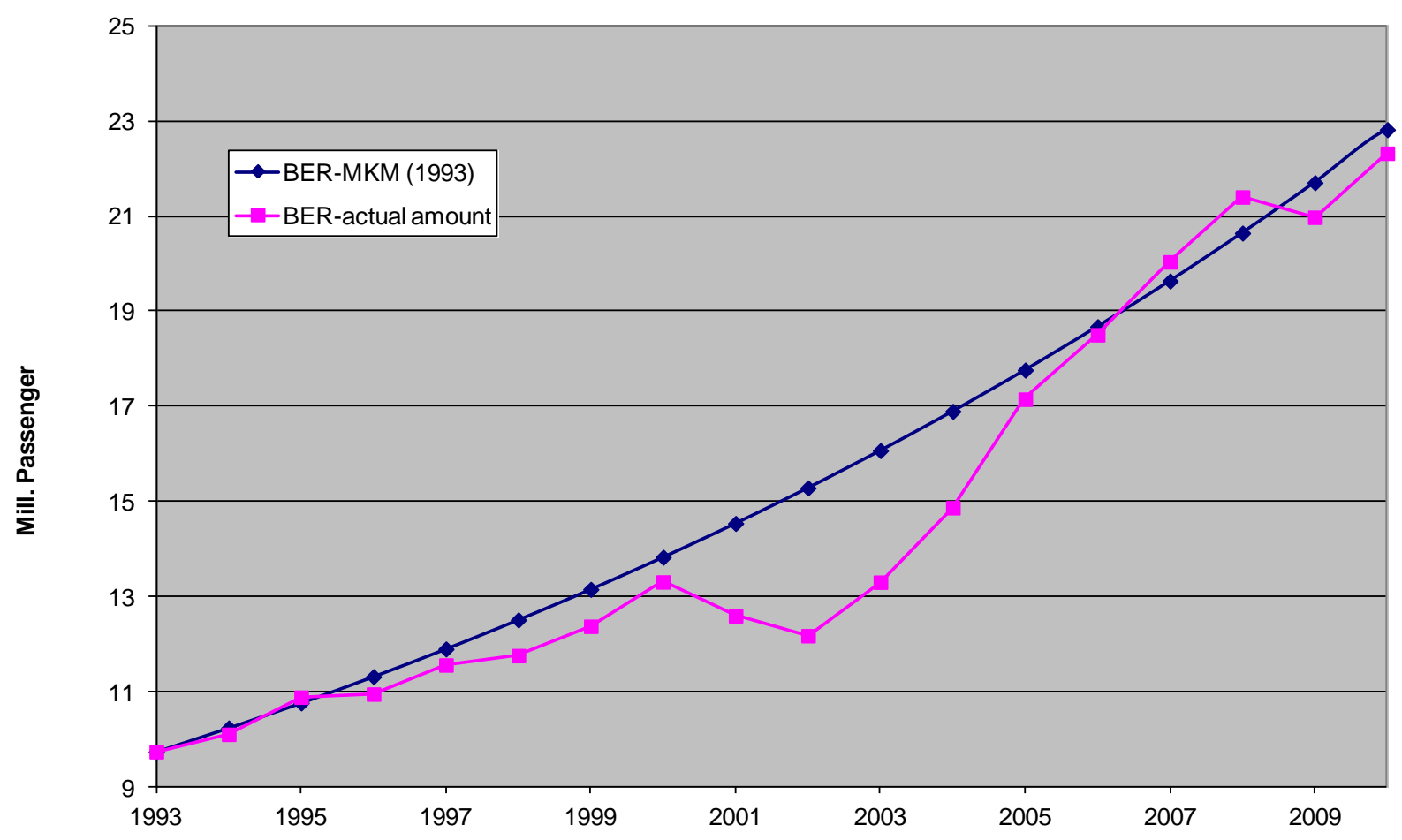

Source: MKmetric GmbH, 2014

It has to be noted that the executed forecast just concerned a point forecast for the year 2010 and the values depicted in the figure are based on an interpolation from 1993 to 2010 for visualisation purposes. 


\section{SUMMARY}

Since the 90's the market conditions for air transport have undergone multiple changes in different sectors. Global drivers have been the liberalisation and deregulation policy as well as the globalisation of economy with new emerging markets. Stable markets have become unstable as economic drivers gain power and unpredictable incidents have direct effect on air transport while in parallel new regulations are imposed locally. In parallel the competitive situation within the aviation world is facing an ongoing consolidation with bankruptcy and mergers but as well raising powerful airlines and airports. New aircrafts change network strategies and new air service products emerged which are marketed differently using new electronic distribution channels. It is obvious that all these developments severely influenced the consumer behaviour.

To stay competitive and to develop air transport further all aviation stakeholders need to understand the consumer behaviour and the related elasticity to service characteristics in detail, but the available traditional data source declines rapidly so that the classic aviation forecasting tools become risky and are of rapidly declining use as IATA stated.

In this paper an alternative way for air transport demand forecasting is outlined reflecting the consumers' decision process. This system approach considers the determinants of transport and airports as well as air services are considered as a part of a competitive transport system linked with surface mode networks. Modelling the consumers' perspective while starting the trip where consumers live and ending a trip where they work or make vacation, vice versa. In consequence mobility is a matter of regional attractiveness and the distribution is influenced by spatial divergence as regions compete for investments and tourists. The accessibility of the regions is determined by a choice set of travel options which concerns a portfolio of alternatives where for air transport originating and destination airport as well as transfer possibilities vary.

The decision taken by the consumers for the transport alternatives from the region of origin to the destination region is modelled in a consistent way of interdependent choice models which reflect the mode choice, airport and route choice, access/egress and slot choice. These models mirror the consumer behaviour using logistic functions whereby the mathematical form is flexible such that threshold and captivities can be captured. The elasticities of consumers to characteristics of the alternatives (e.g. time, cost, frequency, alliance) allow to measure demand effects on changes of the transport system, e.g. services, infrastructure.

This complex modelling approach allows considering local and global competition, and instead of fixed catchments the approach deals with dynamic ones determined by the attractiveness of the alternative transport opportunities available for each trip. Thus overlapping catchments and route competitors for short and long haul services individually can be analysed as the short- or long-term demand forecast for an airport or a route always considers the competitors endogenously as explained by some examples. 
The price to run such a system approach is complexity in modelling, extensive computing power and intensive data collection although the latter are mostly public data but often just available with a delay due to slow publication processes. Other barriers to circumvent are the aviation industry sensitivity to market information preventing access to purchase data, consumer surveys or even aircraft movement data, and the still existing large differences in publication rules for air transport statistics across Europe and throughout the world making the data harmonisation process intensive and the validation process irreplaceable.

\section{ACKNOWLEDGEMENT}

I am grateful to Oliver Schnell for his contributions to the application chapter and his comments on drafts of the paper. The approach outlined builds on a variety of research projects partially supported by the European Commission and the German Federal Ministry of Transport and Digital Infrastructure in combination with airports and airlines. The responsibility for any remaining shortcomings remains the author's. 
